\title{
Biogas Reforming as a Precursor for Integrated Algae Biorefineries: Simulation and Techno-Economic Analysis
}

\author{
Philipp Kenkel ${ }^{1, *(\mathbb{D})}$, Timo Wassermann ${ }^{1,2} \mathbb{D}$ and Edwin Zondervan ${ }^{3}$ \\ 1 Advanced Energy Systems Institute, Department of Resilient Energy Systems, University of Bremen, \\ Enrique-Schmidt Straße 7, 28359 Bremen, Germany \\ 2 Artec Sustainability Research Center, Department of Resilient Energy Systems, University of Bremen, \\ Enrique-Schmidt Straße 7, 28359 Bremen, Germany; timo.wassermann@uni-bremen.de \\ 3 Department of Chemical Engineering, Twente University, 7500 AE Enschede, The Netherlands; \\ e.zondervan@utwente.nl \\ * Correspondence: kenkel@uni-bremen.de
}

Citation: Kenkel, P.; Wassermann, T.; Zondervan, E. Biogas Reforming as a Precursor for Integrated Algae Biorefineries: Simulation and Techno-Economic Analysis. Processes 2021, 9, 1348. https://doi.org/ $10.3390 /$ pr9081348

Academic Editor: Alberto J. Moya

Received: 28 May 2021

Accepted: 27 July 2021

Published: 30 July 2021

Publisher's Note: MDPI stays neutral with regard to jurisdictional claims in published maps and institutional affiliations.

Copyright: (c) 2021 by the authors. Licensee MDPI, Basel, Switzerland. This article is an open access article distributed under the terms and conditions of the Creative Commons Attribution (CC BY) license (https:// creativecommons.org/licenses/by/ $4.0 /)$.

\begin{abstract}
Biogas is a significant by-product produced in algae processing and may be used for many different applications, not only as a renewable energy carrier but also as a chemical intermediate in integrated algae-based biorefineries. In this work, the reforming of biogas to $\mathrm{H}_{2} / \mathrm{CO}_{2}$ mixtures (referred to as SynFeed) as feed for the direct hydrogenation of $\mathrm{CO}_{2}$ to methanol is investigated. Two conventional processes, namely steam methane and autothermal reforming, with upstream $\mathrm{CO}_{2}$ separation from raw biogas are compared to novel concepts of direct biogas bi- and tri-reforming. In addition, downstream $\mathrm{CO}_{2}$ separation from SynFeed using the commercial Selexol process to produce pure $\mathrm{H}_{2}$ and $\mathrm{CO}_{2}$ is considered. The results show that upstream $\mathrm{CO}_{2}$ separation with subsequent steam methane reforming is the most economic process, costing $142.48 € / t_{\text {synFeed, }}$ and taking into consideration the revenue from excess hydrogen. Bi-reforming is the most expensive process, with a cost of $413.44 € / \mathrm{t}_{\mathrm{S} y n F e e d}$, due to the high demand of raw biogas input. Overall, SynFeed from biogas is more economical than SynFeed from $\mathrm{CO}_{2}$ capture and water electrolysis $\left(464 € / \mathrm{t}_{\text {SynFeed }}\right)$, but is slightly more expensive than using natural gas as an input $(107 € /$ SynFeed $)$. Carbon capture using Selexol comes with costs of $22.58-27.19 € / \mathrm{t}_{\mathrm{CO}_{2}}$, where approximately $50 \%$ of the costs are derived from the final $\mathrm{CO}_{2}$ compression.
\end{abstract}

Keywords: biogas reforming; techno-economic analysis; aspen plus; methanol; FAME; HEFA

\section{Introduction}

With climate change considered to be one of the biggest challenges of the current time, the relevance of sustainable fuels and chemicals is ever-growing. Renewable hydrogen $\left(\mathrm{H}_{2}\right)$ and methanol are considered to be next generation energy carriers-up to the socalled hydrogen- and methanol-economies [1]. While $\mathrm{H}_{2}$ is a carbon-free high-caloric gas, methanol is a versatile and easy to handle liquid hydrocarbon. Both chemicals can be utilized for various applications. These include the production of power, heat or synthetic drop-in fuels (e.g., kerosene (HEFA), diesel (FAME) or gasoline) [1,2]. Another application is the production of short chain olefins or aromatic compounds, which are building block chemicals in plastics and solvents production. While $\mathrm{H}_{2}$ and methanol are currently produced mainly on the basis of fossil feedstocks, such as natural gas or coal, an alternative raw material could be biogas [3]. Biogas, a mixture of $\mathrm{CH}_{4}$ and $\mathrm{CO}_{2}$, can be obtained by anaerobic digestion of energy crops or municipal waste, as well as from algae residue.

Algae represent an advanced biomass source, with lower land usage and higher productivity as compared with other types of biomass, while not competing with food production [4,5]. It can be utilized for a plethora of products. Algae refineries (see Figure 1) cultivate algae in water using nutrients and carbon dioxide. The produced algae are harvested and dewatered. The biomass consists of a considerable amount of bio-oil, which 
is separated using solvent extraction (e.g., hexane). These algal oils can be converted to fatty acids methyl esters (FAME), also called biodiesel and glycerol or hydroprocessed esters and fatty acids (HEFA), which are usable as biokerosene. The algae residue, on the other hand, is composed of carbohydrates and proteins and can be used as a feedstock for bioethanol or biogas production $[2,4,5]$. Biogas has many applications, including electricity and steam generation through combustion and the use of gas and steam turbines. However, biogas can also be employed for the production of pure $\mathrm{H}_{2}$ or a mixture of $\mathrm{H}_{2}$ and carbon dioxide $\left(\mathrm{CO}_{2}\right)$ (here referred to as SynFeed) or carbon monoxide (CO) (synthesis gas). Synthesis gas or SynFeed, in turn, can be used for methanol production based on conventional or direct $\mathrm{CO}_{2}$ hydrogenation [1].

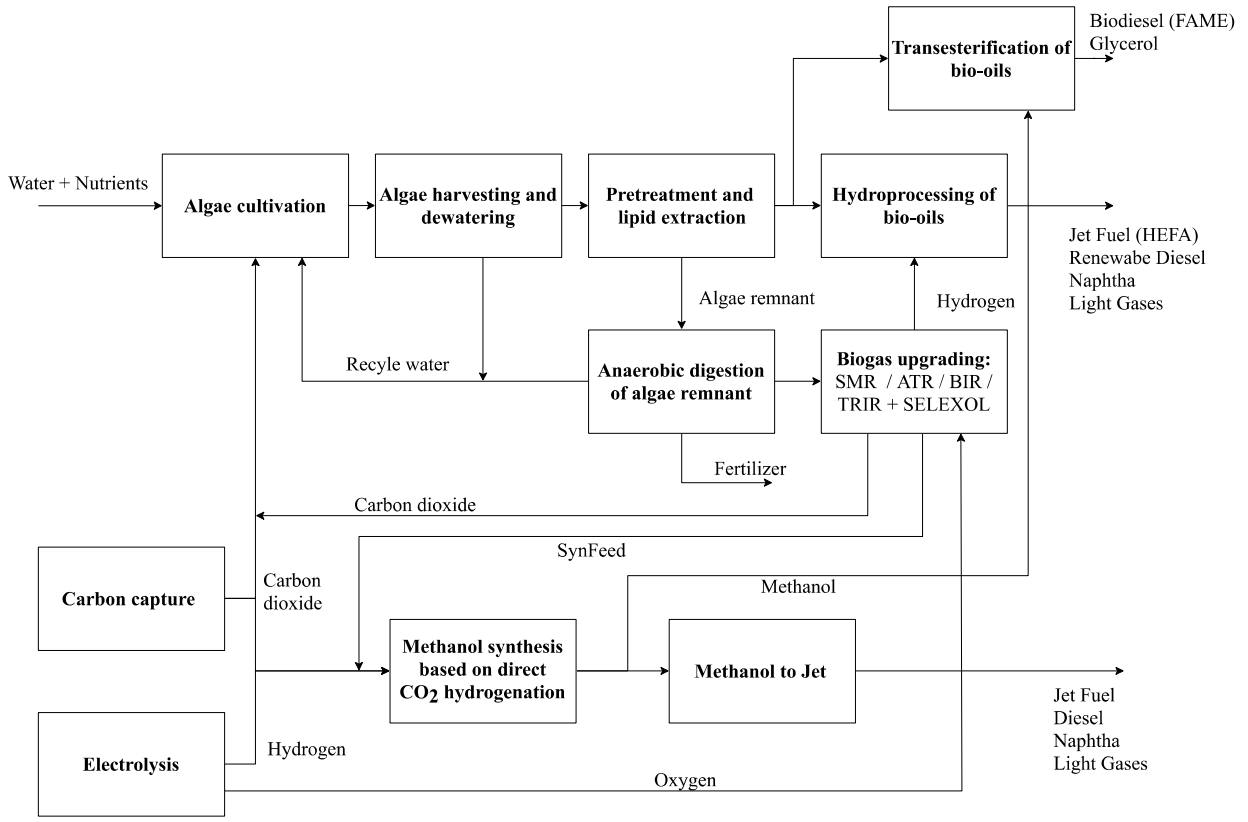

Figure 1. Concept of an integrated algae biorefinery.

Methanol in conjunction with $\mathrm{H}_{2}$ and $\mathrm{CO}_{2}$ are particularly interesting byproducts in an integrated algae-based biorefinery for the production of FAME or HEFA. FAME is produced by transesterification of bio-oils with methanol and is used mainly as a biodiesel blend [4,5]. HEFA, on the other hand, is manufactured by the hydrogenation of bio-oils using $\mathrm{H}_{2}$, and provides a major ASTM certificated way to produce sustainable aviation fuel (SAF) [6-8]. While methanol synthesis can be operated using SynFeed with $\mathrm{H}_{2} / \mathrm{CO}_{2}$ ratio of 3 as feedstock, pure $\mathrm{H}_{2}$ for HEFA production has to be separated from the $\mathrm{CO}_{2}$ first. However, the remaining $\mathrm{CO}_{2}$ should not be considered as waste but can be used as a raw material for algae cultivation. Therefore, the biogas produced from algae residue can be recycled as a raw material for the further upgrading of algal oils to fuels. Figure 1 depicts the concept of such an integrated algae refinery. To estimate costs and efficiencies of such integrated FAME or HEFA concepts, first the biogas upgrading processes have to be fully understood. The conversion of biogas to SynFeed can be designed with different concepts, using steam or autothermal as well as bi- or tri-reforming processes combined with $\mathrm{CO}_{2}$ and $\mathrm{H}_{2}$ capture. The economics of these processes are highly dependent on process performance indicators, such as yield, utility demand, efficiency or the production of byproducts.

Various researchers have produced significant work on the topic of biogas reforming. Zhao et al. 2020, as well as Minh et al. 2018, give a comprehensive overview on methane $\left(\mathrm{CH}_{4}\right)$ and biogas reforming processes in their review papers $[9,10]$. Important technoeconomic investigations were performed by Di Marcoberardino et al., Chein and Hsu, De Rose et al., Mentenegro Camacho et al. and Madeira et al. [11-15]. 
Di Marcoberardino et al. investigated green $\mathrm{H}_{2}$ production from raw biogas using conventional reforming technologies in combination with pressure swing adsorption (PSA) for $\mathrm{H}_{2}$ purification. The focus of their work is on the detailed modeling of pressure swing adsorption modes, leading to $\mathrm{H}_{2}$ costs of 4.00 to $6.50 € / \mathrm{kg} \mathrm{H}_{2}$ compressed to 20 bar [11]. Chein and Hsu produced research about the production of synthesis gas by tri-reforming of biogas using air as oxygen-donor. Their work does not include an economic analysis, however they investigate the influence of different operating conditions, such as pressure, temperature and reactant composition [15]. De Rose et al. performed a multi-criteria and thermodynamic analysis on biogas reforming to synthesis gas in order to detect optimal operational conditions [12]. Mentenegro Camacho et al. investigated the BioRobur reactor concept for the production of $\mathrm{H}_{2}$ by biogas autothermal reforming. Their work concluded that $\mathrm{H}_{2}$ costs of $2.70-5.30 € / \mathrm{kg}$ can be expected at an amortization time of 4 years [13]. Madeira et al. analyzed biogas-based $\mathrm{H}_{2}$ production from cassava waste water plants and identified $\mathrm{H}_{2}$ costs of $0.13 \mathrm{US} \$ / \mathrm{kWh}$, including capital, fuel and maintenance costs at a payback period of 7 years [14].

Integrated algae-based biorefineries, on the other hand, have been investigated by Gong and You, Gebreslassi and Galanopoulos et al. [16-20]. Gong and You investigated the production of biodiesel (FAME) from bio-oil and methanol, the implementing of biogas production from algae residue, $\mathrm{CO}_{2}$ separation from biogas as well as subsequent steam reforming, the mixing of synthesis gas with $\mathrm{CO}_{2}$ and methanol synthesis [17]. Gebreslassie et al. studied biogas production from algae residue, in combination with biogas upgrading and combustion to produce electricity [20]. Galanopoulos et al. optimized an algae refinery integrated with a wheat straw refinery, implementing an additional conversion step of algae residue to bioethanol and levulinic acid [19]. While Gong and You, as well as Gebreslassie, showed that biogas would be utilized to produce required heat and electricity, Galanopoulos showed that integration which results in value-added products can outperform pure energy production [19].

What is missing in these studies to date is a detailed investigation of biogas reforming using different concepts with the goal of SynFeed production, which can be utilized either as a methanol synthesis feedstock or a pure $\mathrm{H}_{2}$ and $\mathrm{CO}_{2}$ feed as would be required in algaebased biorefineries producing either FAME or HEFA. This investigation includes different reforming technologies using either purified $\mathrm{CH}_{4}$ or direct biogas, as well as upgrading technologies like $\mathrm{CO}_{2}$ capture or $\mathrm{H}_{2}$ separation. This work could subsequently be used for further investigations, such as research about integrated algae-based biorefineries. To close this research gap and provide the required data, such as economy-of-scale capital costs, utility demands, operating pressures and temperatures, the work at hand presents a simulation study of different biogas reforming systems for the production of either SynFeed or pure $\mathrm{H}_{2}$ and $\mathrm{CO}_{2}$. The determined process performance indicators are used afterwards for a techno-economic analysis and a comparison of the net production costs of SynFeed in the context of the German energy system.

\section{Methodology}

During residue treatment in an algae refinery, biomass can be converted into biogas by anaerobic digestion. This biogas is comprised of roughly 65 vol.- $\% \mathrm{CH}_{4}$ and 35 vol.- $\%$ of $\mathrm{CO}_{2}$. A subsequent biogas reforming process can be designed in a variety of ways, with each design including upstream dehydration as well as the removal of trace components. After pre-treatment, the conventional design incorporates a pre-capture of $\mathrm{CO}_{2}$, leading to pure $\mathrm{CH}_{4}$, which is then converted to $\mathrm{H}_{2}$ and $\mathrm{CO}_{2}$ by either steam methane or autothermal reforming. Pre-removal of $\mathrm{CO}_{2}$ can be performed using various processes, however pressure swing adsorption is the most widely used process and thus is considered in the current study. A novel concept includes direct biogas reforming as steam- or autothermal biogas reforming, also called bi-and tri-reforming. Here, pre-capture of $\mathrm{CO}_{2}$ is omitted.

To account for novel and renewable concepts, direct $\mathrm{CO}_{2}$ hydrogenation to methanol is considered to be a downstream conversion technology. Such a conversion technology 
would also allow for the integration of $\mathrm{CO}_{2}$ capture units from various flue gases, as well as $\mathrm{H}_{2}$ production from water electrolysis using renewable electricity (ref. Figure 1). The methanol production step is not simulated or integrated in the techno-economic analysis, however it defines the specifications of the final SynFeed product. In order to meet the specification of direct $\mathrm{CO}_{2}$ hydrogenation, raw synthesis gas from biogas/methane reforming has to be further converted to $\mathrm{CO}_{2}$ and $\mathrm{H}_{2}$ by the water gas shift reaction. An additional benefit of this process is that it results in maximizing the $\mathrm{H}_{2}$ share in the raw SynFeed, which allows for a flexible operation as either a SynFeed production unit or pure $\mathrm{H}_{2}$ and $\mathrm{CO}_{2}$ production units. Utilizing these concepts, a total of four different biogas conversion technologies are considered, as well as $\mathrm{CO}_{2}$ capture from SynFeed mixtures for $\mathrm{H}_{2}$ production (ref. Figure 2). The selected technology for $\mathrm{CO}_{2}$ capture from raw SynFeed in this study is physical absorption using Selexol. This technology is highly developed, is operated at an industrial scale and favors high $\mathrm{CO}_{2}$ contents as well as operating pressures. As such, it is an optimal choice for $\mathrm{CO}_{2}$ capture from biogas/methane reformers. In the Chapters 2.1 to 2.5 , the different process concepts are presented. The simulation models are then described in Chapter 3 and the process performance indicators, as well as economic key figures, are presented in Chapter 4.

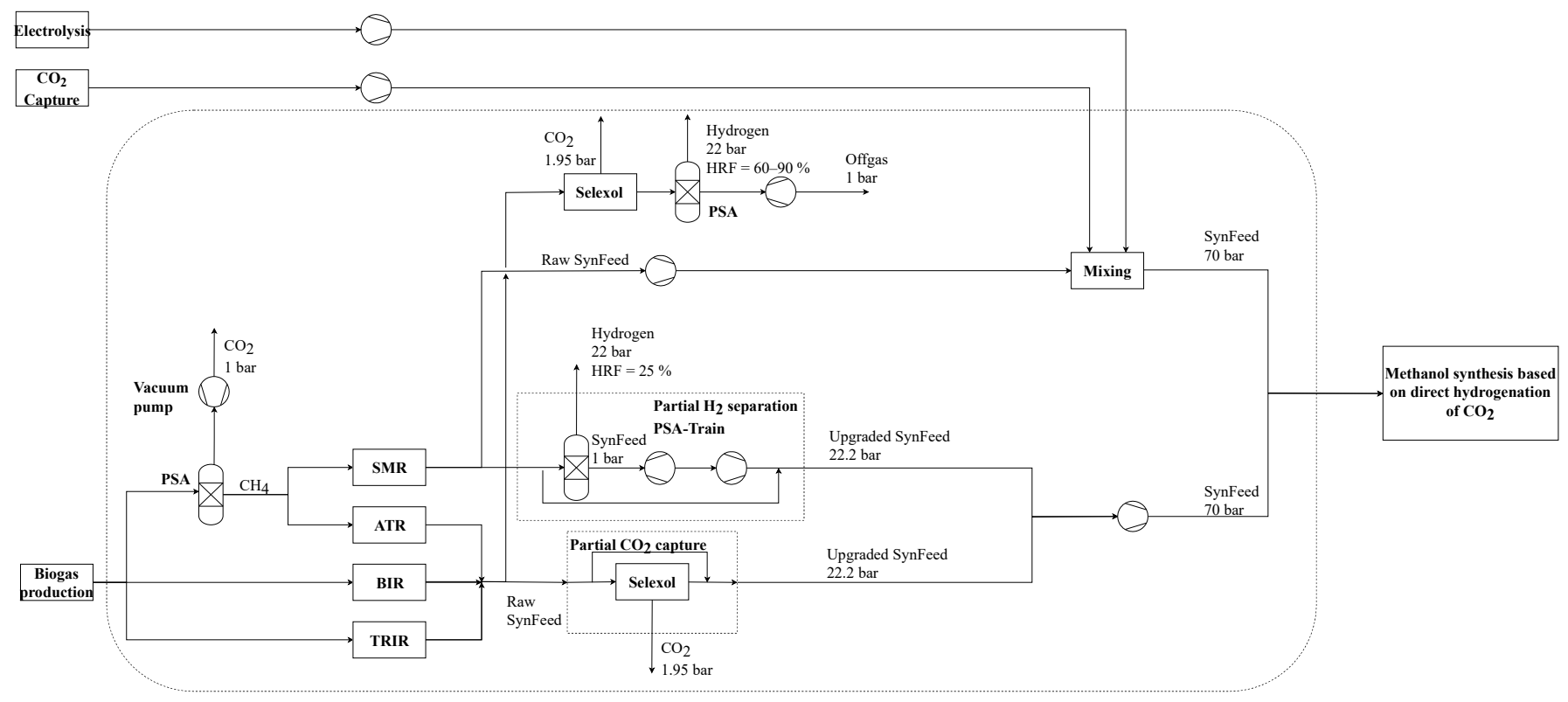

Figure 2. Biogas upgrading pathways for application in integrated biorefineries and power-to-x concepts.

\subsection{Steam Methane Reforming (SMR)}

Steam reforming of methane is a prominent way to produce synthesis gas or $\mathrm{H}_{2}$; the former being feed for methanol or Fischer-Tropsch-Synthesis, and the latter being a major input for oil refineries or ammonia production [3]. Industrial steam reformers are designed for small- to large-scale $\mathrm{H}_{2}$ output of $1000-200,000 \mathrm{Nm}^{3} / \mathrm{h}$, with $50,000 \mathrm{Nm}^{3} / \mathrm{h}$ being a typical capacity [10]. In steam methane reforming (SMR), $\mathrm{CH}_{4}$ reacts with steam over a nickel-based catalyst via the endothermic reaction Equation (1) to form CO and $\mathrm{H}_{2}$ [3]. Due to its endothermic nature and a surplus of substance on the product site, the equilibrium of this reaction is shifted to the product site by high temperatures and low pressures. Based on Equation (1), an equilibrium steam to carbon ratio (S/C) for SMR is reached at 1 . The process is often operated at high temperatures of $700-900{ }^{\circ} \mathrm{C}$ and elevated pressures of 20-40 bar [3,21]. Higher temperatures can lead to coke formation, while lower temperatures can reduce $\mathrm{CH}_{4}$ conversion [10]. The effect of the pressure on $\mathrm{CH}_{4}$ conversion is rather small compared to that of the temperature, while lower pressures account for higher conversion. Pressures of 20-40 bar are chosen anyway, due to reduced 
equipment size and lower capital expenditures, as well as down-stream processing at high pressures [22]. The decreased $\mathrm{CH}_{4}$ conversion due to high pressures is offset, to some extent, by an elevated S/C of 3-5.

Besides the steam reforming reaction, nickel-based catalysts also promote the watergas-shift (WGS) reaction (Equation (2)). This reaction is slightly exothermic and is responsible for $\mathrm{CO}_{2}$ formation from $\mathrm{CO}$. Due to its exothermic nature, the WGS reaction is favored at low temperatures.

$$
\begin{aligned}
& \mathrm{CH}_{4}+\mathrm{H}_{2} \mathrm{O} \rightleftharpoons 3 \mathrm{H}_{2}+\mathrm{CO}, \Delta \mathrm{H}_{\mathrm{R}}=206 \mathrm{~kJ} / \mathrm{mol} \\
& \mathrm{CO}+\mathrm{H}_{2} \mathrm{O} \rightleftharpoons \mathrm{H}_{2}+\mathrm{CO}_{2}, \Delta \mathrm{H}_{\mathrm{R}}=-41 \mathrm{~kJ} / \mathrm{mol}
\end{aligned}
$$

If $\mathrm{H}_{2}$, rather than synthesis gas, is the target product of the reforming process, $\mathrm{CO}$ is not desired in the product stream. In addition, a maximum conversion of $\mathrm{CH}_{4}$ and a maximum yield of $\mathrm{H}_{2}$ is desired. If lower pressures are not practicable, higher S/C ratios are appropriate in order to maximize $\mathrm{CH}_{4}$ conversion. Additionally, WGS reaction is enhanced by one or two additional WGS reactors. Often, these are designed as one high temperature water-gas-shift (HT-WGS) reactor and one low temperature water-gas-shift (LT-WGS) reactor. HT-WGS reactors operate at temperatures of $300-500{ }^{\circ} \mathrm{C}$ using $\mathrm{Fe} / \mathrm{Cr}$ or Co/Mo catalysts, while LT-WGS operate at $190-280^{\circ} \mathrm{C}$ using $\mathrm{CuO} / \mathrm{ZnO}$ catalysts $[3,21]$. The dual reactor design is used to take advantage of the higher reaction rates at elevated temperatures and higher conversion at lower temperatures, thus minimizing capital costs while maximizing $\mathrm{H}_{2}$ yield.

\subsection{Autothermal Methane Reforming (ATR)}

Another prominent way to produce synthesis gas or $\mathrm{H}_{2}$ is by autothermal reforming (ATR). This process combines the partial oxidation of $\mathrm{CH}_{4}$ (Equation (3)) with steam reforming (Equation (1)).

$$
\mathrm{CH}_{4}+\frac{1}{2} \mathrm{O}_{2} \rightleftharpoons \mathrm{CO}+2 \mathrm{H}_{2}, \Delta \mathrm{H}_{\mathrm{R}}=-36 \mathrm{~kJ} / \mathrm{mol}
$$

ATR can also be used to produce synthesis gas from longer hydrocarbons, such as gasoline or naphtha [3]. The combination of endothermic steam reforming and exothermic partial oxidation ensures a high $\mathrm{H}_{2}$ yield, while transforming the process into an autothermal process where the partial oxidation supplies the heat needed for the reforming process [3]. Industrial reactors are designed as one unit-operation which utilizes two reaction zones. At the top, fuel as well as oxygen (or air) and steam are fed into the reactor and fuel and oxygen $\left(\mathrm{O}_{2}\right)$ are then partially oxidized, supplying heat. The reacted gas mixture then enters a tubular reaction zone filled with nickel catalysts in order to perform the reforming reactions. Operating temperatures of $850-1100^{\circ} \mathrm{C}$ are slightly higher than in conventional steam reformers, while pressure is in the same range with 20-70 bar $[3,23,24]$. Due to higher operating temperatures, as well additional partial oxidation reforming of $\mathrm{CH}_{4}$ and $\mathrm{O}_{2}, \mathrm{CH}_{4}$, conversion is generally higher when using ATR compared to SMR, while $\mathrm{H}_{2} / \mathrm{CO}_{2}$ ratio is generally lower. Another advantage of using ATR is that the $\mathrm{H}_{2} / \mathrm{CO}$ ratio can be adjusted by tuning the $\mathrm{S} / \mathrm{C}$ and $\mathrm{O}_{2} / \mathrm{C}$ ratio.

\subsection{Biogas Steam Reforming/Bi-Reforming (BIR)}

Direct steam reforming of biogas is also called steam biogas reforming (BGR) or bireforming (BIR). In bi-reforming, steam reforming reaction (Equation (1)) is accompanied by the dry reforming of $\mathrm{CH}_{4}$ and $\mathrm{CO}_{2}$ according to Equation (4), due to the presence of $\mathrm{CO}_{2}$ in the feed.

$$
\mathrm{CH}_{4}+\mathrm{CO}_{2} \rightleftharpoons 2 \mathrm{CO}+2 \mathrm{H}_{2}, \Delta \mathrm{H}_{\mathrm{R}}=247 \mathrm{~kJ} / \mathrm{mol}
$$


The reaction is endothermic and favors high temperatures and low pressures. Often, the $\mathrm{CH}_{4} / \mathrm{CO}_{2}$ ratio in bi-reforming systems is considered to be an important design parameter. However, in this work this parameter was fixed due to the given composition of the biogas. Other process variables are the reforming temperature $\left(500-1000{ }^{\circ} \mathrm{C}\right)$, as well as the pressure (1-40 bar) and S/C ratio (3-5, similar to SMR) [9]. In the literature, bi-reforming processes are often described as being designed at a lower pressure (6-16 bar) and slightly lower temperatures of $800-850^{\circ} \mathrm{C}$, yielding higher $\mathrm{CH}_{4}$ and $\mathrm{CO}_{2}$ conversion $[9,11]$.

\subsection{Biogas Autothermal Reforming/Tri-Reforming (TRIR)}

Biogas autothermal reforming, better known as tri-reforming (TRIR), combines bireforming with partial oxidation. Accordingly, Equations (1)-(4) take place in TRIR. $\mathrm{O}_{2}$ for partial oxidation is supplied as air or pure $\mathrm{O}_{2}$. Pure $\mathrm{O}_{2}$ leads to higher purities in the product stream but is costly to produce. Studies investigating the thermodynamic behavior of TRIR indicate similar pressures as the other processes with 1-20 bar and high temperatures of $800{ }^{\circ} \mathrm{C}-1000{ }^{\circ} \mathrm{C}$. Often, low pressures at around 1 bar with temperatures at the low end of $800^{\circ} \mathrm{C}$ are investigated $[9,11,15]$.

\section{5. $\mathrm{CO}_{2}$ Capture by Selexol Process}

The presented reforming technologies produce $\mathrm{H}_{2} / \mathrm{CO}_{2}$ gas mixtures of different ratios. For some of the processes, a partial $\mathrm{CO}_{2}$ capture has to be incorporated in order to meet the $\mathrm{H}_{2} / \mathrm{CO}_{2}$ ratio specification required for direct $\mathrm{CO}_{2}$ hydrogenation methanol synthesis. Another approach is to produce pure $\mathrm{CO}_{2}$ and $\mathrm{H}_{2}$ as stand-alone products from the SynFeed. In both cases, $\mathrm{CO}_{2}$ capture is an integral part of the process design.

The most commonly used technologies for $\mathrm{CO}_{2}$ capture are chemical absorption (MEA and MDEA), physical absorption (Selexol, Rectisol) or pressure swing adsorption [25]. While chemical absorption relies on low pressure steam for solvent regeneration, physical absorption and pressure swing adsorption rely on pressure relief in combination with cooling.

Carbon capture using physical absorption is especially interesting for streams with a high $\mathrm{CO}_{2}$ content and partial pressure. The Selexol process is one of the most advanced physical absorption processes and utilizes a mixture of polyethylene glycols as the solvent. Due to its high affinity to $\mathrm{H}_{2} \mathrm{~S}$, this process can be designed for dual-extraction, capturing $\mathrm{H}_{2} \mathrm{~S}$ and $\mathrm{CO}_{2}$ separately or together [25]. This feature makes it interesting for a sulfur-rich gasification feed such as coal. However, in methane reforming systems, catalysts are sensitive to sulfur. Therefore, it is expected that sulfur components will be removed prior to the biogas reforming. Thus, the Selexol process can be designed as a single-stage extraction which reduces capital and operating costs.

\section{Process Simulation}

Process models for SMR, ATR, BIR, TRIR and Selexol carbon capture were developed. The models are implemented in Aspen Plus V10.

As in other literature-based studies, the Peng-Robinson equation of state is utilized in the process models for reforming technologies [11,12]. $\mathrm{CO}_{2}$ capture by Selexol requires more complex solvent-gas interaction and is therefore modeled using PC-SAFT [26,27]. All the reforming processes are designed for a base capacity of $1000 \mathrm{kmol} / \mathrm{h}$ gas input, where SMR and ATR use pure $\mathrm{CH}_{4}(16 \mathrm{t} / \mathrm{h}), \mathrm{BIR}$ and TRIR use raw biogas with a $\mathrm{CH}_{4} / \mathrm{CO}_{2}$ ratio of $0.65 / 0.35(25.8 \mathrm{t} / \mathrm{h})$. This amount of biogas roughly corresponds to an algae refinery producing about 61 million liters ( $46 \mathrm{kt}$ ) of jet fuel per year via hydro-processing of algae oil [28]. The base feed load for the Selexol units is the SynFeed output of the respective reforming technology. 


\subsection{Process Design and Modeling of SMR Process}

As described above, the SMR process is designed for high $\mathrm{CH}_{4}$ conversion as well as high $\mathrm{H}_{2}$ yield and low $\mathrm{CO}$ content in order to be utilized as either feed in direct hydrogenation of $\mathrm{CO}_{2}$ to methanol or as $\mathrm{H}_{2}$ feed in HEFA production using algal oil.

The process flow diagram is presented in Figure 3. It is assumed that $\mathrm{CO}_{2}$ is separated from the biogas beforehand, leading to a pure $\mathrm{CH}_{4}$ input. First, this pure $\mathrm{CH}_{4}$ is compressed in a two-stage compression with intercooling to $40^{\circ} \mathrm{C}$. Afterwards the gas feed is pre-heated to $500{ }^{\circ} \mathrm{C}$ and mixed with steam at $500{ }^{\circ} \mathrm{C}$ to the desired S/C ratio. Here, two different approaches are taken and investigated independently from each other.

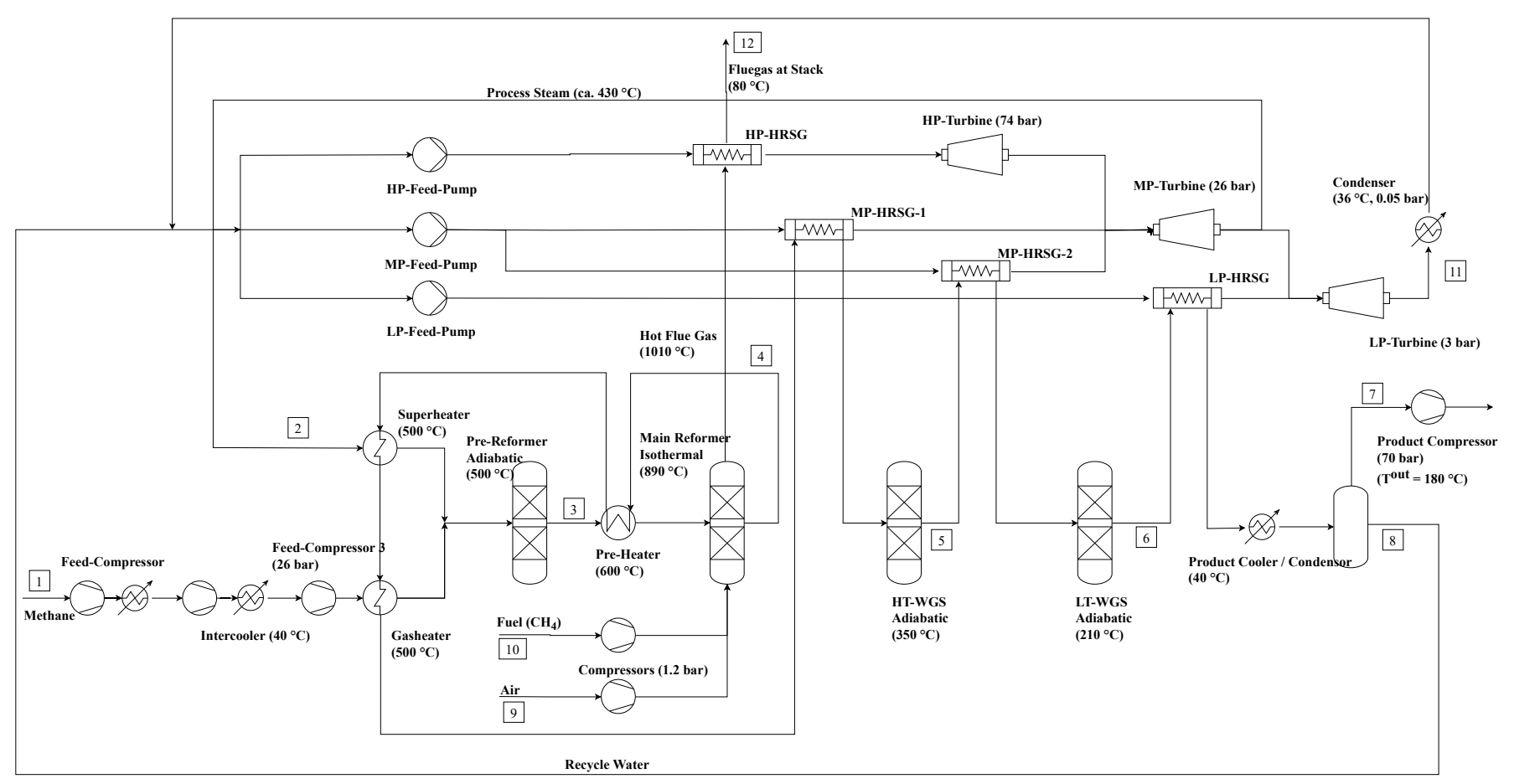

Figure 3. Process flow diagram of the SMR process (Stream details for flows 1-12 in Appendix E).

The first approach is a medium $S / C=3.5$, which is a common value for SMR. In this layout, the $\mathrm{CH}_{4}$ conversion is $<90 \%$, which is not critical in common applications. Unreacted off-gas is simply used as fuel for the heat integration of the conversion reactor. However, in this study the target process is the direct hydrogenation methanol synthesis using the complete product gas from the reforming process. Impurities, such as remaining $\mathrm{CH}_{4}$, lead to higher volume flows which would require larger equipment, thus they should be minimized. The other concepts that are investigated (ATR, BIR, TRIR) also yield higher conversion rates and, thus, lower impurities. To counter this effect and ensure a fair comparison of technologies, a second S/C ratio of 5 is investigated. Here, a conversion of at least $95 \%$ is achieved, leading to low $\mathrm{CH}_{4}$ impurities of maximum 1 mol.- $\%$ in the product stream. The mixture of steam and $\mathrm{CH}_{4}$ is fed into an adiabatic pre-reformer. Such reformers are normally used to break down longer hydrocarbons of fossil feedstock. Here it is used to guarantee that only short-chain hydrocarbons enter the main reformer. The pre-reformer is modeled as a Gibbs reactor. After pre-reforming, the gas mixture is pre-heated to $600{ }^{\circ} \mathrm{C}$ using the hot outlet from the main reformer. In industry, the main reformer is designed as a tubular reactor with external burners. Here it is modeled as two Gibbs reactors. The first one is the reformer itself, which operates at $890{ }^{\circ} \mathrm{C}$ and performs the endothermic steam reforming and slightly exothermic WGS reaction. This reactor represents the tubular catalytic reformer part. The second reactor represents the external burners. Here, additional $\mathrm{CH}_{4}$ fuel is mixed with air at $15 \% \mathrm{O}_{2}$ excess. The fuel-air mixture is reacted to provide the 
required heat for the reforming reaction. The flue gas temperature is set at $1010{ }^{\circ} \mathrm{C}$, while the fuel input is designed for full heat supply of the main reformer.

The hot flue gas is used to generate superheated steam at 74 bar and $600{ }^{\circ} \mathrm{C}$. This steam is depressurized in the first steam turbine to 26 bar in order to generate electricity. The hot reformer outlet is cooled in several steps. At first, it is used to pre-heat the pre-reformer outlet. Following this, it is utilized to superheat the steam/methane feed to the pre-reformer to $500{ }^{\circ} \mathrm{C}$. Finally, the remaining heat is used to evaporate and superheat water at 26 bar. After this series of heat exchanges, the reformer outlet enters the HT-WGS at $350{ }^{\circ} \mathrm{C}$. The HT-WGS is modeled as an equilibrium reactor that performs the WGS-reaction at adiabatic conditions. The hot WGS outlet is then cooled down to $210^{\circ} \mathrm{C}$, generating steam at 26 bar. Part of the medium pressure steam is used as the feed for the reformer. This share depends on the S/C configuration. The rest of the medium pressure steam mixture is depressurized in a MP-steam turbine to $3 \mathrm{bar}$, in order to generate electricity. The cold WGS outlet enters the LT-WGS reactor, which is also modeled as an adiabatic equilibrium reactor, performing the reaction at $210{ }^{\circ} \mathrm{C}$. Some of the heat of the LT-WGS outlet is recovered in order to produce 3 bar LP-steam, which is mixed with the MP-turbine outlet and depressurized to 0.25 bar in a LP-steam turbine. The LP-turbine outlet is afterwards condensed at about $36^{\circ} \mathrm{C}$ and pumped to working pressures by several feed pumps. The cooled WGS-outlet is further cooled to $40^{\circ} \mathrm{C}$, utilizing cooling water. Afterwards it is injected into a flash drum, separating water and product gases. While the water is recycled and used as an input for the feed pumps, the gases, containing mainly $\mathrm{H}_{2}$ and $\mathrm{CO}_{2}$, are compressed to 70 bar for methanol synthesis using a product compressor.

In this study, the final product compressor is taken as a decisive unit-operation for the reforming operation pressure. The inlet temperature, as well as outlet pressure, are fixed at $40{ }^{\circ} \mathrm{C}$ and 70 bar. A single-stage compression should be applied, and the outlet temperature of the compressor should not exceed $180^{\circ} \mathrm{C}$. By further defining pressure drops in the unit-operations, the feed pressure is determined. Pressure drops for reactors, heat exchanger and heat recovery units are taken from the literature, while pressure stages for the different turbines are designed based on experience.

To properly size and cost heat exchangers, the thermal transmittance $U$ for each exchanger is calculated based on the VDI-Wärmeatlas using Equations (5)-(7) [29]. Here U-values for the Gas-Gas as well as the Liquid-Liquid heat exchanger are assumed to be linear depending on pressure, while waste heat recovery has a fixed value. Where heat exchangers have multiple roles in one (e.g., economizing (liq.-liq.), evaporation (HRSG) and super heating (gas-gas)), a mean value based on the amount of heat exchanged for the different types of heat exchange is calculated. Table 1 shows the calculated U-values for the described model.

$$
\begin{gathered}
\mathrm{U}^{\mathrm{G}-\mathrm{G}}=1.533 \cdot \mathrm{p}+18.467 \\
\mathrm{U}^{\mathrm{G}-\mathrm{L}}=1.294 \cdot \mathrm{p}+41.206 \\
\mathrm{U}^{\mathrm{HRSG}}=32.5
\end{gathered}
$$

\begin{tabular}{|c|c|c|c|c|c|c|}
\hline HE & $\begin{array}{l}\text { Total Amount of } \\
\text { Heat (MW) }\end{array}$ & PMEAN (Bar) & $\begin{array}{c}\text { Gas-Gas } \\
\%\end{array}$ & $\underset{\%}{\text { Evap. }}$ & Gas-Liq. $\%$ & $\begin{array}{l}\text { U-Value } \\
\left(\mathrm{W} / \mathrm{m}^{2} \mathrm{~K}\right)\end{array}$ \\
\hline LP-HRSG & 3.67 & 13.05 & 3.40 & 78.90 & 17.90 & 39.43 \\
\hline MP-HRSG 1 & 23.48 & 25.25 & 21.60 & 52.40 & 26.00 & 48.15 \\
\hline MP-HRSG 2 & 14.88 & 24.90 & 10.60 & 59.90 & 29.50 & 46.53 \\
\hline HP-HRSG & 70.56 & 37.80 & 21.50 & 42.35 & 36.15 & 45.67 \\
\hline Pre-Heater & 12.48 & 24.95 & 100.00 & 0 & 0 & 56.71 \\
\hline Gas-Heater & 4.89 & 25.20 & 100.00 & 0 & 0 & 56.95 \\
\hline Super-heater & 2.35 & 25.20 & 100.00 & 0 & 0 & 57.09 \\
\hline
\end{tabular}

Table 1. Calculated U-Values for different heat exchanger in SMR X95 case. 
Modeling the reactors as Gibbs or equilibrium reactors simplifies the simulation tremendously, however it is not completely accurate. While the reforming and WGS reaction are fast at the assumed temperatures, the real equilibrium is not reached in industrial reactors. Gibbs and equilibrium reactors assume an infinite reaction time. However, real reforming processes operate at small residence times of about $1 \mathrm{~s}$ [22]. To balance this offset, the temperature approach method suggested by Hamelinck et al., as well as Katofsky, is used [22,24]. It allows for a definition of a temperature offset at which the equilibrium composition is calculated, while the energy balances are performed at the real reactor temperatures. This leads to a slightly reduced conversion and therefore to a more realistic representation. Table 2 shows all the important key parameters for the SMR process design.

Table 2. Key modeling parameters for SMR Process.

\begin{tabular}{|c|c|c|c|}
\hline Parameter & Value & Note & Ref. \\
\hline Feed pressure/Reformer & $26 \mathrm{bar} / 25.1 \mathrm{bar}$ & $\begin{array}{l}\text { Based on outlet temperature of } \\
180^{\circ} \mathrm{C} \text { max and pressure drops. }\end{array}$ & \\
\hline $\begin{array}{c}\text { Pre-Reformer } \\
\text { Temperature/Approach }\end{array}$ & $\begin{array}{c}500{ }^{\circ} \mathrm{C} \\
\text { Delta } \mathrm{T}=-10^{\circ} \mathrm{C}\end{array}$ & & {$[22,30]$} \\
\hline Pre-Reformer pressure drop & -0.5 bar & & {$[22,24]$} \\
\hline Reformer Temperature/Approach & $\begin{array}{c}890^{\circ} \mathrm{C} \\
\text { Delta } \mathrm{t}=-10^{\circ} \mathrm{C}\end{array}$ & & {$[22,30]$} \\
\hline Reformer pressure drop & -0.5 bar & & [24] \\
\hline Heat exchange pressure drop & -0.2 bar & & [22] \\
\hline HRSG pressure drop & $\begin{array}{l}-0.5 \text { bar liquid site } \\
-0.2 \text { bar gas site }\end{array}$ & & [22] \\
\hline HT-WGS pressure drop & $-0.5 \mathrm{bar}$ & & {$[22,24]$} \\
\hline HT-WGS Temperature/Approach & $\begin{array}{c}350{ }^{\circ} \mathrm{C} \\
\text { DeltaT }=10^{\circ} \mathrm{C}\end{array}$ & & {$[21,22,24]$} \\
\hline LT-WGS pressure drop & -0.5 bar & & {$[22,24]$} \\
\hline LT-WGS Temperature/Approach & $\begin{array}{c}210^{\circ} \mathrm{C} \\
\text { Delta } \mathrm{T}=20^{\circ} \mathrm{C}\end{array}$ & $\begin{array}{c}\text { Temperature approach higher due to } \\
\text { lower reaction rate at } \\
\text { lower temperatures }\end{array}$ & {$[21,22]$} \\
\hline HP-TUR Inlet/Outlet pressure & $74 / 26$ & $\begin{array}{l}\text { Outlet pressure chosen based on } \\
\text { required feed pressure }\end{array}$ & Experience \\
\hline MP-TUR Inlet/Outlet pressure & $26 / 3$ bar & & Experience \\
\hline LP-TUR Inlet/Outlet pressure & $3 \mathrm{bar} / 0.25$ & $\begin{array}{l}\text { Based on } 0.05 \text { bar outlet at condenser } \\
\text { with } 0.2 \text { pressure drop }\end{array}$ & - \\
\hline Efficiency Pumps/Compressors & $\begin{array}{c}80 \% \text { isentropic } \\
100 \% \text { mechanical }\end{array}$ & & Experience \\
\hline Efficiency Turbine & $\begin{array}{l}89 \% \text { isentropic } \\
99 \% \text { mechanical }\end{array}$ & & {$[24]$} \\
\hline U-Values for HE & $\begin{array}{c}\text { Calculated based on linearized } \\
\text { values }\end{array}$ & & [29] \\
\hline Steam to Carbon ratio & 3.5 and 5 & $\begin{array}{l}\text { Based on literature and } 95 \% \\
\qquad \mathrm{CH}_{4} \text { Conversion }\end{array}$ & [24] \\
\hline
\end{tabular}

\subsection{Process Design and Modeling of ATR Process}

The general concept of autothermal reforming is similar to steam reforming and is depicted in Figure 4. Steam and $\mathrm{CH}_{4}$ are pressurized to operating pressure and, afterwards, are heated to $500{ }^{\circ} \mathrm{C}$ for adiabatic pre-reforming. After pre-reforming the mixture is fed to the autothermal reactor. Additionally, pure $\mathrm{O}_{2}$ is fed to the reactor. In general, the ATR can be operated using air or $\mathrm{O}_{2}$. However, air leads to diluted streams with a high content of nitrogen, requiring the complex separation of $\mathrm{H}_{2}$ and $\mathrm{CO}_{2}$. In addition, the process idea originates from integrated renewable processes, so it stands to reason that $\mathrm{O}_{2}$ is available as a byproduct of water electrolysis. The pre- and main-reformer are designed as adiabatic Gibbs reactors. The hot outlet is used for heat integration and then fed to the dual-stage WGS at $350{ }^{\circ} \mathrm{C}$ and $210^{\circ} \mathrm{C}$. The WGS outlet is also used in the heat integration, and then cooled to $40^{\circ} \mathrm{C}$ and flashed. The gaseous product is compressed to 70 bar. 


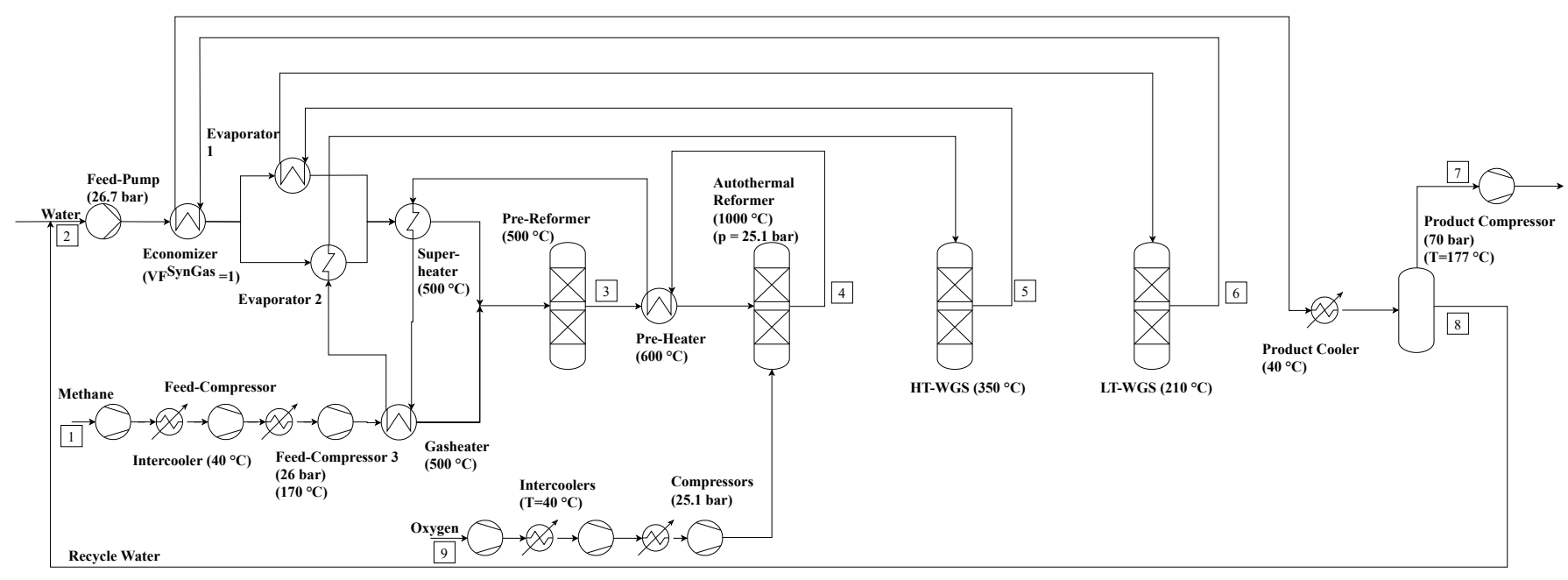

Figure 4. Process flow diagram of the ATR process.

The autothermal process concept has various design variables. These include the S/C ratio, which can be lower or equal to the SMR process (0.5-3.5); the reformer pressure, which is between 20-70 bar; and the $\mathrm{O}_{2} / \mathrm{C}$ ratio, which is often around the partial oxidation stoichiometric value or higher $[3,23,24]$. Directly connected to the $S / C$ and $\mathrm{O}_{2} / \mathrm{C}$ ratio is the reformer temperature, which is in the range of $850-1100{ }^{\circ} \mathrm{C}[3,23,24]$.

In order to constrain the design of the ATR to some extent, the following design principles are considered:

1. The CO-content in the compressed product is limited to $1 \mathrm{~mol}-\mathrm{-} \%$, since it serves as feed for direct hydrogenation methanol synthesis;

2. the required heat is provided by heat integration of the partially oxidized feed, so that the ATR process is fully autothermal;

3. the amount of $\mathrm{O}_{2}$ supplied is minimized, due to its energy-, emission- and costintensive provision.

To meet the CO-design criterion, the $\mathrm{S} / \mathrm{C}$ ratio is set to $2.2 / 1$. If the ratio is further increased, the $\mathrm{CO}$ content is further reduced, but more energy is required for steam generation, which leads to either external heat demand or the need for a higher $\mathrm{O}_{2}$ supply. To meet autothermal design (design principle 2) at an S/C ratio of 2.2, the reformer outlet temperature has to be at least $999^{\circ} \mathrm{C}$. To achieve this temperature, a superstoichiometric $\mathrm{O}_{2}$ supply is necessary. While it is possible to further increase the reformer temperature and thus generate excess energy that could be transformed into steam or electricity, this would contradict design principle 3 due to increased $\mathrm{O}_{2}$ demand. Therefore, the $\mathrm{O}_{2} / \mathrm{C}$ ratio is set at 0.574 in order to reach exactly $999^{\circ} \mathrm{C}$. As with the SMR process, U-values for heat exchangers are calculated using Equations (5)-(7). The resulting values are depicted in Table 3. The key parameters as well as literature references for the ATR design are provided in Table 4.

Table 3. Calculated U-Values for ATR Process heat exchanger.

\begin{tabular}{|c|c|c|c|c|c|c|}
\hline HE & $\begin{array}{l}\text { Total Amount } \\
\text { of Heat (MW) }\end{array}$ & $\begin{array}{c}P_{\text {MEAN }} \\
\text { Bar }\end{array}$ & $\begin{array}{c}\text { Gas-Gas } \\
\%\end{array}$ & $\begin{array}{c}\text { Evap. } \\
\%\end{array}$ & Gas-Liq.\% & $\begin{array}{c}\text { U-Value } \\
\left(\mathrm{W} / \mathrm{m}^{2} \mathrm{~K}\right)\end{array}$ \\
\hline $\mathrm{ECO}$ & 4.43 & 24.65 & 0 & 0 & 100 & 7.10 \\
\hline EVAP 1 & 11.71 & - & 0 & 100 & 0 & 32.50 \\
\hline EVAP 2 & 15.33 & - & 0 & 100 & 0 & 32.50 \\
\hline Super heater & 6.62 & 25.20 & 100 & 0 & 0 & 57.10 \\
\hline Gas-Heater & 4.89 & 25.10 & 100 & 0 & 0 & 57.00 \\
\hline
\end{tabular}


Table 4. Key modeling parameters for ATR Process.

\begin{tabular}{|c|c|c|c|}
\hline Parameter & Value & Note & Ref. \\
\hline Feed pressure (Reformer) & 25.1 bar & $\begin{array}{l}\text { Based on similar design to } \\
\text { SMR/Outlet temperature and } \\
\text { pressure drops }\end{array}$ & \\
\hline $\begin{array}{c}\text { Pre-Reformer } \\
\text { Temperature/Approach }\end{array}$ & $\begin{array}{c}500{ }^{\circ} \mathrm{C} \\
\text { Delta } \mathrm{T}=-10{ }^{\circ} \mathrm{C}\end{array}$ & & {$[22,30]$} \\
\hline Pre-Reformer pressure drop & $-0.5 \mathrm{bar}$ & & {$[22,24]$} \\
\hline Reformer Temperature/Approach & $\begin{array}{c}999^{\circ} \mathrm{C} \\
\text { Delta } \mathrm{t}=-10^{\circ} \mathrm{C}\end{array}$ & Based on design principles & \\
\hline Reformer pressure drop & -0.5 bar & & [24] \\
\hline Heat exchange pressure drop & $-0.2 \mathrm{bar}$ & & [22] \\
\hline HRSG pressure drop & -0.5 bar liquid site -0.2 bar gas site & & [22] \\
\hline HT-WGS pressure drop & -0.5 bar & & {$[22,24]$} \\
\hline HT-WGS Temperature/Approach & $\begin{array}{c}350{ }^{\circ} \mathrm{C} \\
\text { DeltaT }=10^{\circ} \mathrm{C}\end{array}$ & & {$[21,22,24]$} \\
\hline LT-WGS pressure drop & -0.5 bar & & {$[22,24]$} \\
\hline LT-WGS Temperature/Approach & $\begin{array}{c}210^{\circ} \mathrm{C} \\
\text { Delta } \mathrm{T}=20^{\circ} \mathrm{C}\end{array}$ & $\begin{array}{l}\text { Temperature approach higher due to } \\
\text { lower reaction rate at lower } \\
\text { temperatures }\end{array}$ & {$[21,22]$} \\
\hline Efficiency Pumps/Compressors & $\begin{array}{c}80 \% \text { isentropic } \\
100 \% \text { mechanical }\end{array}$ & & Experience \\
\hline U-Values for HE & Calculated based on linearized values & & [29] \\
\hline Steam to Carbon ratio & $2.2: 1$ & Based on design principles & \\
\hline Oxygen to Carbon ratio & $0.574: 1$ & Bases on design principles & \\
\hline
\end{tabular}

\subsection{Process Design and Modeling of BIR}

The design of the bi-reforming process is based on the SMR process. In the literature, standard temperatures and pressures of $800-860^{\circ} \mathrm{C}$ and $6-16$ bars are presented $[9,11,15]$. However, pressures of 16 bar are too low to achieve the targeted design with a single-stage product compression. Therefore, the reforming pressure is adjusted to $25.1 \mathrm{bar}$, which is equal to SMR and ATR pressure. As a result of the elevated pressure, the temperature as well as the $\mathrm{S} / \mathrm{C}$ ratio must be increased in order to guarantee a minimum $\mathrm{CH}_{4}$ conversion of $95 \%$. The maximum temperature values described in the literature correspond to $1000{ }^{\circ} \mathrm{C}$, although a more conservative approach is taken here with $\mathrm{T}=890^{\circ} \mathrm{C}$ (SMR Basis). The ratio of steam and $\mathrm{CH}_{4}$ is set to 5 , based on the $\mathrm{SMR}$ process. Together with the $\mathrm{CO}_{2}$ from the biogas, the $\mathrm{S} / \mathrm{C}$ is 3.25 . U-values are calculated using the same approach as in the SMR process, while all the remaining parameters are taken from the SMR case. Figure 5 shows the process flow diagram of the bi-reforming process.

\subsection{Process Design and Modeling of TRIR}

The TRIR process is modeled based on the autothermal reformer system. The design is also constrained by the three design principles defined for the ATR mentioned in Chapter 3.2. The $\mathrm{S} / \mathrm{C}$ and $\mathrm{O}_{2} / \mathrm{C}$ ratios are designed in order to achieve high $\mathrm{CH}_{4}$ conversion, while supplying all the required heat internally. The operating pressure of the reformer is once again limited by the product compressor outlet temperature. The final design specifies a reformer outlet temperature of $962{ }^{\circ} \mathrm{C}$ and $\mathrm{CH}_{4} / \mathrm{H}_{2} \mathrm{O} / \mathrm{O}_{2}$ ratio of $0.65 / 1.63 / 0.39$. Due to a similar heat exchanger network design, U-values are identical to the ATR case, as are the remaining parameters. The process flow diagram is shown in Figure 6. 


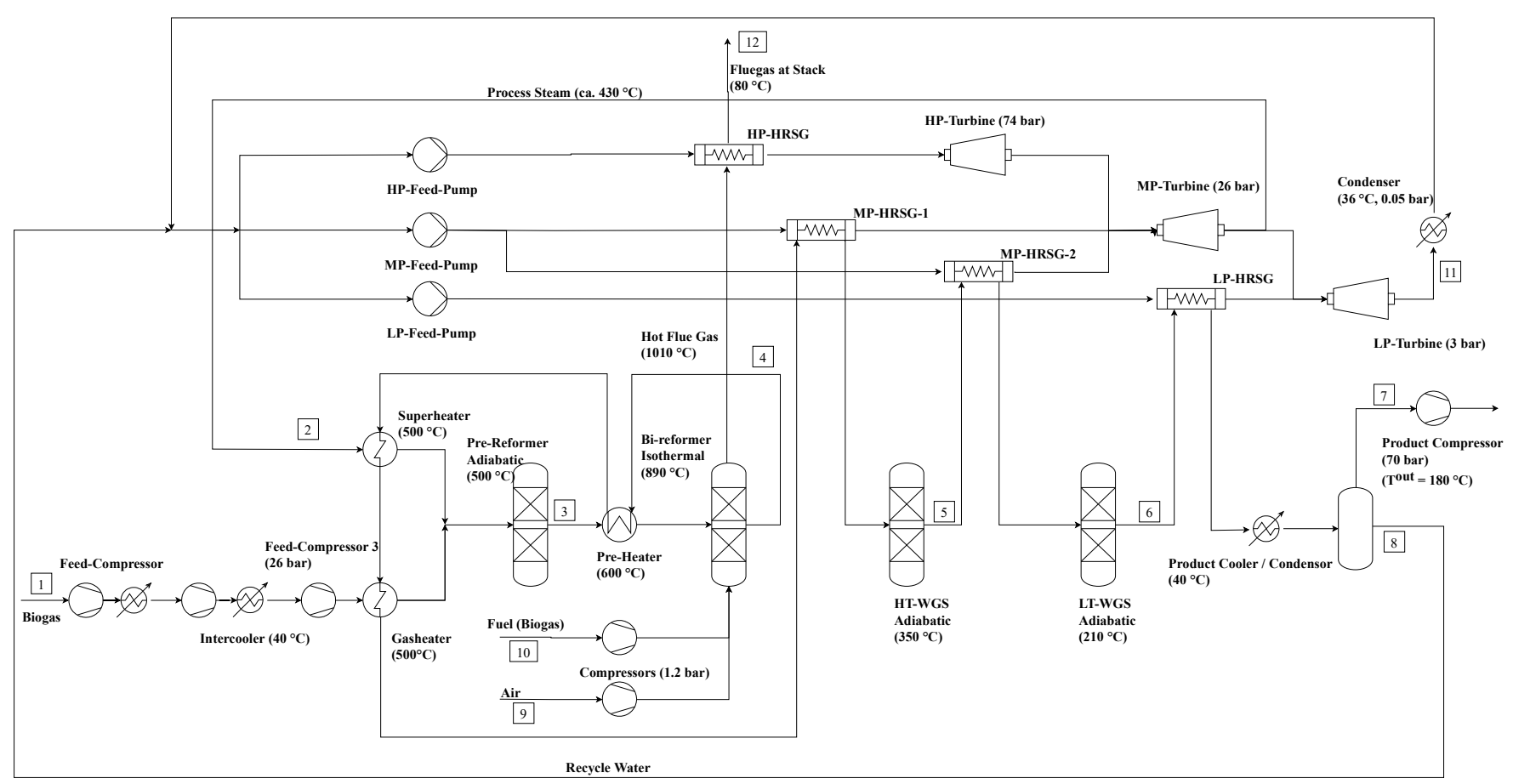

Figure 5. Process flow diagram of the bi-reforming process design.

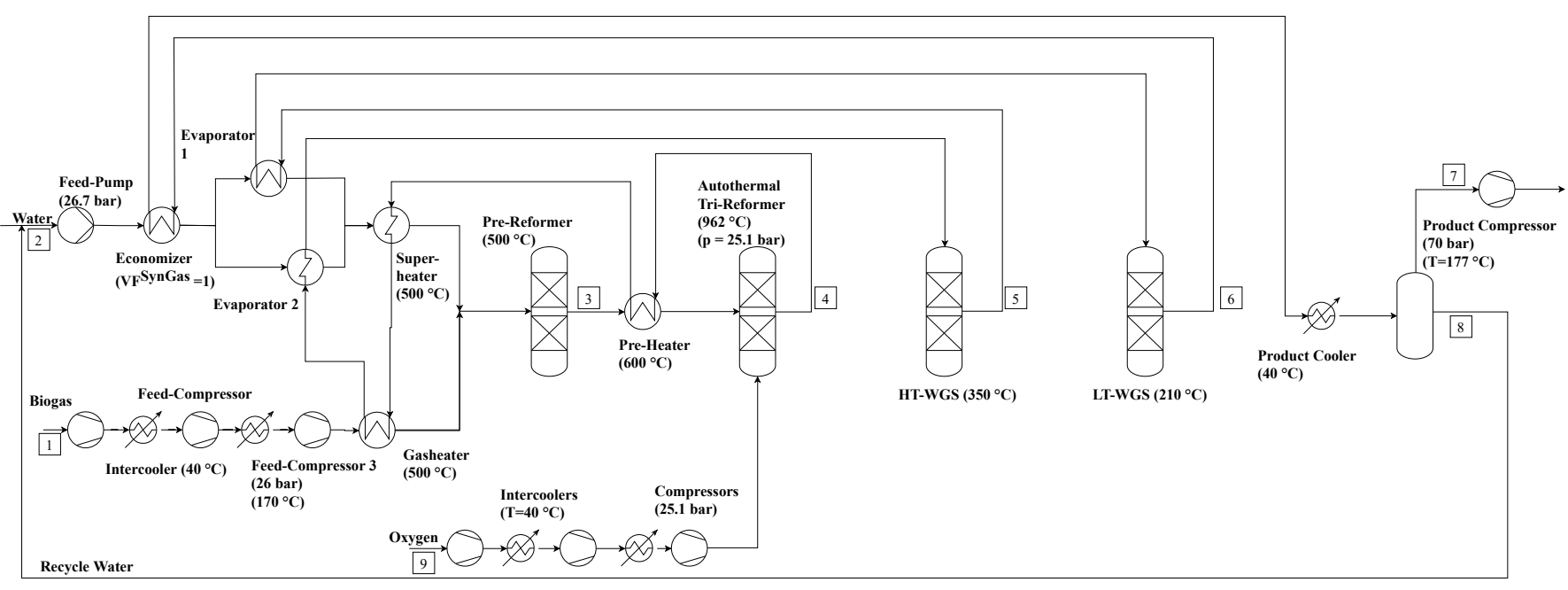

Figure 6. Process flow diagram of the tri-reforming process (Stream details for flows 1-9 in Appendix E).

\subsection{Process Design and Modeling of Selexol Process}

The process design of a single-stage Selexol $\mathrm{CO}_{2}$ capture process is depicted in Figure 7. The cooled product gas from the steam reforming unit enters an absorber column at $40{ }^{\circ} \mathrm{C}$ and feed pressure of 22.2 bar. The absorber tower is operating at 22.2 bar. While the gas stream enters the tower at the bottom, a lean Selexol $/ \mathrm{H}_{2} \mathrm{O}$ mixture at $-1{ }^{\circ} \mathrm{C}$ enters the tower at the top. The liquid and the gas pass the column in a countercurrent flow. During this process, the $\mathrm{CO}_{2}$ and some amount of $\mathrm{H}_{2}$ are dissolved into the solvent while releasing heat. After the capture process, the rich solvent is depressurized in a hydro-turbine to 10.5 bar and then flashed adiabatically. The resulting gaseous stream is recompressed to 22.2 bar, cooled down to $40^{\circ} \mathrm{C}$ and consequently recycled back to the absorption column bottom. This is done in order to recycle most of the captured $\mathrm{H}_{2}$. The goal is to produce a high concentration of $\mathrm{CO}_{2}$ and $\mathrm{H}_{2}$, hence capturing $\mathrm{H}_{2}$ along with $\mathrm{CO}_{2}$ is undesirable. 


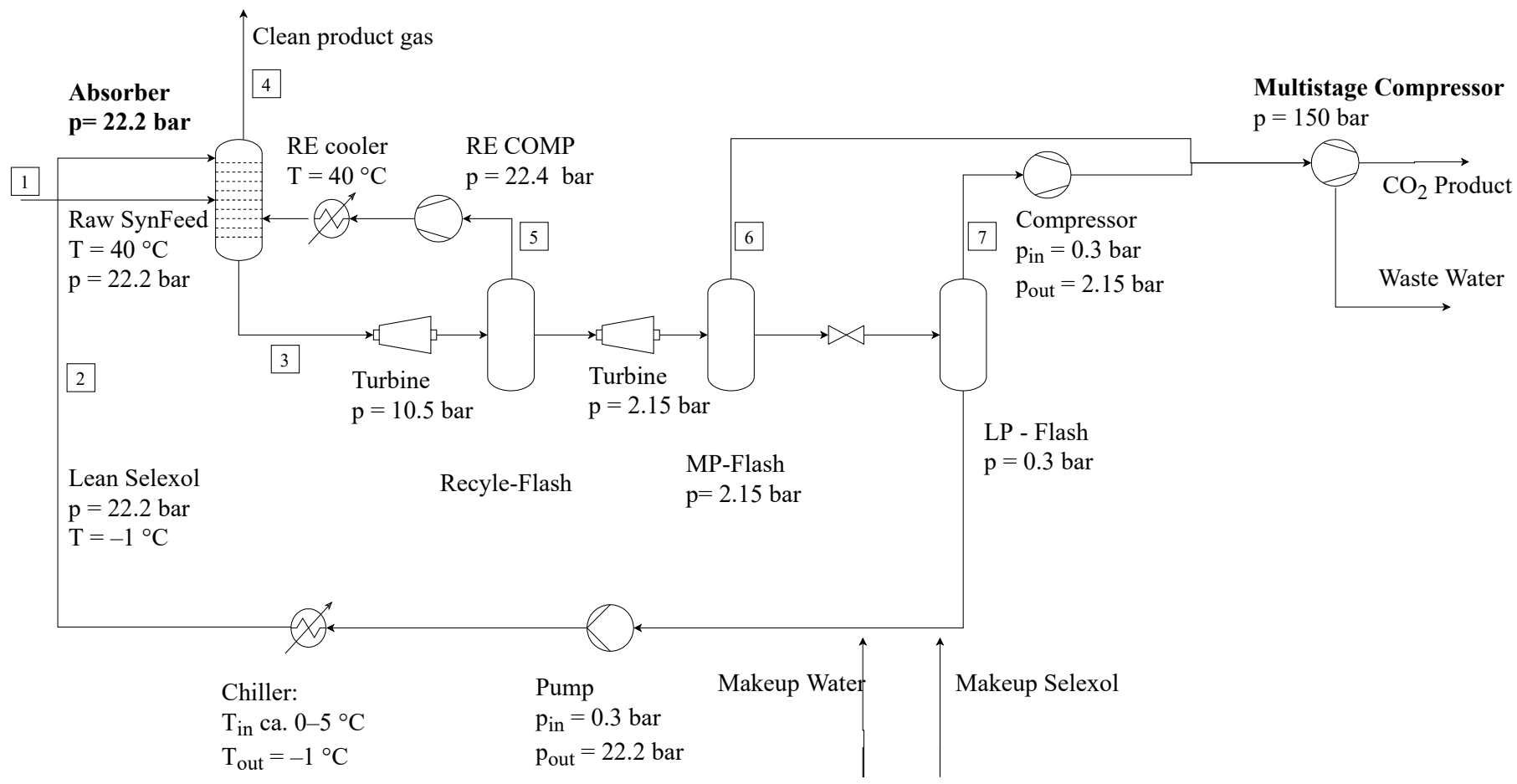

Figure 7. Process flow diagram of Selexol $\mathrm{CO}_{2}$-capture unit (Stream details for flows 1-7 in Appendix E).

After $\mathrm{H}_{2}$ recycling, the remaining rich solvent is depressurized in two steps to 2.15 bar and 0.3 bar. The first step is performed by a turbine; the second step by a valve and vacuum pumps. The cleaned solvent is mixed with make-up water and Selexol to account for losses in degassing. Afterwards, it is pumped to feed pressure and cooled to feed temperature by a chilling unit. The degassed $\mathrm{CO}_{2}$ flows are compressed and mixed consecutively. The resulting raw $\mathrm{CO}_{2}$ stream is available at 1.95 bar and $40{ }^{\circ} \mathrm{C}$. These settings are tailored for use in algae cultivation or, rather, algae-based biorefineries. To provide additional information and to be able to compare $\mathrm{CO}_{2}$ capture costs with other process concepts investigated in the literature, a subsequent compression to 150 bar was implemented (e.g., for transportation or storage). This compression is achieved using a multistage compressor with three compression units, intermediate cooling to $40{ }^{\circ} \mathrm{C}$ and subsequent condensate separation.

The carbon capture process is designed individually for all four types of biogas reformers. Due to the different $\mathrm{H}_{2} / \mathrm{CO}_{2}$ ratios, the amount of solvent required per ton of input gas, as well as the make-up Selexol and water requirements, vary. Common to all four cases is a $\mathrm{CO}_{2}$ capture rate of $90 \%$. Table 5 shows the key modeling parameters of the Selexol process.

Table 5. Key parameters of the Selexol process [27,31,32].

\begin{tabular}{cccc}
\hline Equilibrium Stages & $\begin{array}{c}\text { Pressure Drops in } \\
\text { HE }\end{array}$ & $\begin{array}{c}\text { Intercooling } \\
\text { Temperature }\end{array}$ & $\begin{array}{c}\text { Isentropic Efficiency } \\
\text { of Compressor, } \\
\text { Pump and Turbine }\end{array}$ \\
\hline 12 & $0.2 \mathrm{bar}$ & $40{ }^{\circ} \mathrm{C}$ & $80 \%$ \\
\hline
\end{tabular}

\section{Results}

In the following, the results of the simulations are presented. First, the process performance indicators for all processes, namely the SMR, ATR, BIR, TRIR and Selexol processes, are shown. These indicators include purchase equipment costs, utility and raw material demand, as well as inlet and outlet flow rates and compositions. Provision of these data enables other scientist to reproduce and investigate biogas reforming processes 
customized to their own set of background data (e.g., utility costs, operating hours etc.). After the presentation of process performance indicators, a techno-economic assessment is performed to present the net production costs of the SynFeed, as well as the carbon capture costs of $\mathrm{CO}_{2}$. The reforming systems are customized to the German energy system. Finally, a sensitivity analysis is presented, and the results are discussed in terms of an integrated biorefinery concept.

\subsection{Process Performance Indicators of Biogas Reforming}

\subsubsection{Stream Characteristics}

The product compositions of the different reforming technologies are presented in Table 6. The mass flows of all the concepts are in the scale of $47-50 \mathrm{t} / \mathrm{h}$. The $\mathrm{H}_{2}$ output ranges from $3.5 \mathrm{t} / \mathrm{h}$ (TRIR) to $7.6 \mathrm{t} / \mathrm{h}$ (SMR), which corresponds to 40,000 to $80,000 \mathrm{Nm}^{3} / \mathrm{h}$ and depicts conventional reforming capacities. A detailed stream table can be found in Appendix E.

Table 6. Outlet flow compositions.

\begin{tabular}{cccccc}
\hline & SMR $(\mathbf{S} / \mathbf{C}=\mathbf{3 . 5})$ & SMR $(\mathbf{S} / \mathbf{C}=\mathbf{5})$ & BIR & TRIR & ATR \\
\hline $\mathrm{H}_{2} \mathrm{O}($ mole.- $\%)$ & 00.31 & 0.31 & 0.33 & 0.33 & 0.31 \\
$\mathrm{CO}_{2}$ (mole.- $\left.\%\right)$ & 19.09 & 19.53 & 27.51 & 35.01 & 25.35 \\
$\mathrm{CO}($ mole.- $\%)$ & 0.48 & 0.24 & 0.38 & 0.80 & 0.73 \\
$\mathrm{H}_{2}$ (mole.- $\left.\%\right)$ & 77.80 & 78.88 & 70.88 & 63.62 & 73.35 \\
$\mathrm{CH}_{4}$ (mole.- $\left.\%\right)$ & 2.32 & 1.04 & 0.91 & 0.24 & 0.26 \\
\hline
\end{tabular}

Steam reforming processes achieve superstoichiometric $\mathrm{H}_{2} / \mathrm{CO}_{2}$ ratios of around 4 , while the ATR process reaches slightly under the stoichiometric ration of 2.8. Biogas reforming systems show the lowest ratios of 2.5 and 1.8 for BIR and TRIR, respectively. These results show that SMR would need additional $\mathrm{CO}_{2}\left(\right.$ or $\mathrm{H}_{2}$ separation) for utilization in methanol synthesis, while all the other processes would require additional $\mathrm{H}_{2}\left(\right.$ or $\mathrm{CO}_{2}$ separation). While $\mathrm{H}_{2}$ concentration varies from $63.6 \mathrm{~mol} .-\%$ (TRIR) to $78.8 \mathrm{~mol} .-\%$ (SMR 5 ), $\mathrm{CO}_{2}$ content varies from 19 mol.- $\%\left(\mathrm{SMR}_{3.5}\right)$ to 35 mol.-\% (TRIR). This variation also indicates different behavior during the process of possible $\mathrm{CO}_{2}$ capture using Selexol.

The rate of conversion of $\mathrm{CH}_{4}$ is lowest for the $\mathrm{SMR}_{3.5}$, at $89 \%$. SMR 5 and BIR result in a higher rate of conversion at around 95\%, while autothermal reforming processes (ATR and TRIR) show nearly complete $\mathrm{CH}_{4}$ conversion at $99 \%$. Resulting $\mathrm{CH}_{4}$ impurities in the product gas are measured at 2 mol.- $\%$ for $\mathrm{SMR}_{3.5}$, while other designs are at mol- $1 \%$ or lower. CO impurities are measured at below 1 mol.- $\%$ for all processes, with the steam reforming processes having the lowest levels.

Process concepts based on steam reforming require external burners for their heat supply. The hot flue gas is used for heat recovery and electricity generation. In the end, the flue gas is vented at around $80^{\circ} \mathrm{C}$ into the environment. A detailed stream table for the flue gases which were produced is shown in Appendix E. Conventional SMR processes produce slightly more flue gas than biogas reforming systems due to the different $\mathrm{S} / \mathrm{C}$ ratio. Because the BIR process uses biogas, and therefore less $\mathrm{CH}_{4}$ in the feed, the amount of steam required is also diminished, resulting in less demand for heat and combustion energy. The $\mathrm{CO}_{2}$ concentrations of the flue gases are around 13 to 19 mass.- $\%$. If the potential of carbon recycling is considered, $\mathrm{CO}_{2}$ could be captured by well-known processes such as chemical absorption using MEA.

\subsubsection{Purchase Equipment Costs}

Table 7 lists the calculated purchase equipment costs of the different process designs. Since the product gas compressor to 70 bar is only required if the raw SynFeed is directly fed to the methanol synthesis, the corresponding costs are represented separately. The reformer, as well as the dual water-gas-shift reactor, are calculated using values drawn from the literature and given in Table 8. Base flow rates (FBase), costs (CBase) and sizing 
exponents (fs) for reference plants are given. The approach is based on economies of scale, as shown in Equation (9) with year-dependent chemical engineering plant indices CECPI $[33,34]$. The compressor and balance of plant (BOP), including heat exchangers, pumps, turbines and flash evaporators, are derived from the Aspen Economic Analyzer tool. Equipment for steam reforming technologies (SMR/BIR) are more expensive than that of autothermal systems (ATR/TRIR) because they incorporate a more complex heat recovery system.

$$
\mathrm{EC}_{\mathrm{u}}[\mathrm{M} €]=\mathrm{C}_{\text {Base }}[\mathrm{M} €] \cdot\left(\frac{\mathrm{F}_{\mathrm{u}}}{\mathrm{F}_{\text {Base }}}\right) \mathrm{f}^{\mathrm{s}} \cdot \frac{\mathrm{CECPI}_{\mathrm{u}}}{\mathrm{CECPI}_{\text {Base }}}
$$

Table 7. Purchase equipment costs of different reforming systems.

\begin{tabular}{cccccc}
\hline & SMR $(\mathbf{S} / \mathbf{C}=\mathbf{3 . 5})$ & SMR $(\mathbf{S} / \mathbf{C}=5)$ & BIR & TRIR & ATR \\
\hline EC BOP $\left(\epsilon_{2018}\right)$ & $30,541,322.00$ & $39,727,869.50$ & $31,985,502.50$ & $10,256,641.75$ & $12,251,979.00$ \\
$\quad$ EC Product & $2,169,700.25$ & $2,169,700.25$ & $1,920,610.25$ & $1,765,921.75$ & $1,990,915.00$ \\
compressor $\left(\epsilon_{2018}\right)$ & & & & & \\
$\quad$ EC Reformer & $6,445,000.00$ & $6,585,800.00$ & $5,264,800.00$ & $1,876,400.00$ & $2,429,900.00$ \\
$\quad$ system $\left(\epsilon_{2018}\right)$ & $5,780,000.00$ & $6,085,900.00$ & $4,254,400.00$ & $3,204,100.00$ & $4,711,200.00$ \\
$\quad$ EC Dual WGS & & & & \\
Reformer $\left(\epsilon_{2018}\right)$ & & & & & \\
\hline
\end{tabular}

Table 8. Literature values for base costs for reforming equipment.

\begin{tabular}{|c|c|c|c|c|c|}
\hline Unit-Operation & Base Costs $\left(\mathrm{C}_{\text {Base }}\right)$ & Base Flow $\left(\mathrm{F}_{\text {Base }}\right)$ & Sizing Exponent $\left(f^{s}\right)$ & Fixed Capital Investment Factor $\left(\mathrm{f}_{\mathrm{u}}^{\mathrm{I}}\right)$ & Reference \\
\hline Reformer & $9.40 \mathrm{M} \$_{2001}$ & $1390.00 \mathrm{kmol} / \mathrm{h}$ input $\mathrm{CH}_{4}$ & 0.60 & 2.30 & [24] \\
\hline WGS & $36.90 \mathrm{M} \$_{2001}$ installed & $15.60 \mathrm{Mmol} / \mathrm{h} \mathrm{CO}+\mathrm{H}_{2}$ input & 0.85 & 1.00 & {$[24]$} \\
\hline ATR & $4.70 \mathrm{M} \$_{2001}$ & $1390.00 \mathrm{kmol} / \mathrm{h}$ input $\mathrm{CH}_{4}$ & 0.60 & 2.30 & [24] \\
\hline
\end{tabular}

\subsubsection{Utility and Raw Material Demands}

Table 9 lists the major utility and raw material demands. The electricity demand is highly dependent on the process concept. Steam reforming concepts (SMR/BIR) are electricity producers, whereas autothermal concepts (ATR/TRIR) are designed for solely self-support and therefore do not produce electricity. The electric load of the product compressor is highest for SMR, followed by ATR and BIR. The lowest electric load is required by the TRIR process. This is explained by the $\mathrm{H}_{2} / \mathrm{CO}_{2}$ ratio in the product gas. With an increasing ratio, the electric load increases due to a higher effort being required for $\mathrm{H}_{2}$ compression compared to $\mathrm{CO}_{2}$ compression. ATR and TRIR are autothermal units and therefore no heat supply is calculated. SMR and BIR use additional fuel to supply 74 and $51 \mathrm{MW}$ of heat respectively.

Table 9. Calculated utility and materials demand.

\begin{tabular}{|c|c|c|c|c|c|}
\hline & SMR $(S / C=3.5)$ & $\operatorname{SMR}(\mathrm{S} / \mathrm{C}=5)$ & BIR & TRIR & ATR \\
\hline Electricity BOP (MW) & -10.14 & -6.97 & -7.37 & 4.75 & 5.40 \\
\hline Electricity Product compressor (MW) & 5.62 & 5.91 & 4.23 & 3.35 & 4.64 \\
\hline Cooling $(\mathrm{MW})$ & 56.46 & 67.02 & 54.25 & 21.24 & 25.98 \\
\hline Gas input $(\mathrm{t} / \mathrm{h})$ & 25.68 & 26.62 & 45.41 & 25.83 & 16.04 \\
\hline Share fuel & 0.38 & 0.40 & 0.43 & 0.00 & 0.00 \\
\hline Share reformer & 0.62 & 0.60 & 0.57 & 1.00 & 1.00 \\
\hline Water demand $(\mathrm{t} / \mathrm{h})$ & 63.05 & 90.08 & 58.55 & 29.28 & 39.72 \\
\hline Water recycle $(\mathrm{t} / \mathrm{h})$ & -30.99 & -55.79 & -36.32 & -20.52 & -25.03 \\
\hline Air $/ \mathrm{O}_{2}$ demand $(\mathrm{t} / \mathrm{h})$ & 190.04 & 208.57 & 155.82 & 12.59 & 18.38 \\
\hline
\end{tabular}




\subsubsection{Economy of Scale for Reforming Technologies}

While the operating costs (e.g., electricity, water and reformer feed) are linear and dependent on the size of the plant, this is not the case for the capital costs. To gain a deeper understanding on how economies of scale affect the conversion process, two additional cases are simulated. Flow rates are modified as follows, while the remaining parameter set is kept constant:

- A small-scale case with reformer input of $10 \mathrm{kmol} / \mathrm{h}_{\mathrm{CH} 4}$, which is equivalent to $345 \mathrm{Nm}^{3} / \mathrm{h}$ biogas as reformer feed and about $600 \mathrm{Nm}^{3} / \mathrm{h}$ biogas as total feed for steam reforming. This corresponds to a $2.5 \mathrm{MW}_{\mathrm{el}}$ biogas plant;

- a medium-scale case of halved capacity of $500 \mathrm{kmol} / \mathrm{h}_{\mathrm{CH} 4}$ reformer inlet.

Figures 8 and 9 show the dependency of purchase equipment costs on the inlet flow rate of the different plant layouts, as well as the subsequent product compressor providing compression from 22.2 bar to 70 bar. Often, equipment costs are described by power laws for small capacity changes. However, due to the large capacity range in this context, the equipment costs are instead represented by a linear expression. Even though linear capital cost functions are less detailed then power laws, they are of interest for the purpose of simple costing over large capacity ranges. As can be observed in Figure 8, the equipment costs of the allothermal steam reforming systems are higher and also have a steeper rise of cost escalation. This effect is due to the requirement for turbines and large waste heat recovery units. For very small capacities of around $10 \mathrm{kmol} / \mathrm{h}$ gas input, this effect is preserved, however the costs are nearly equal, indicating a trade-off point at small production capacities.

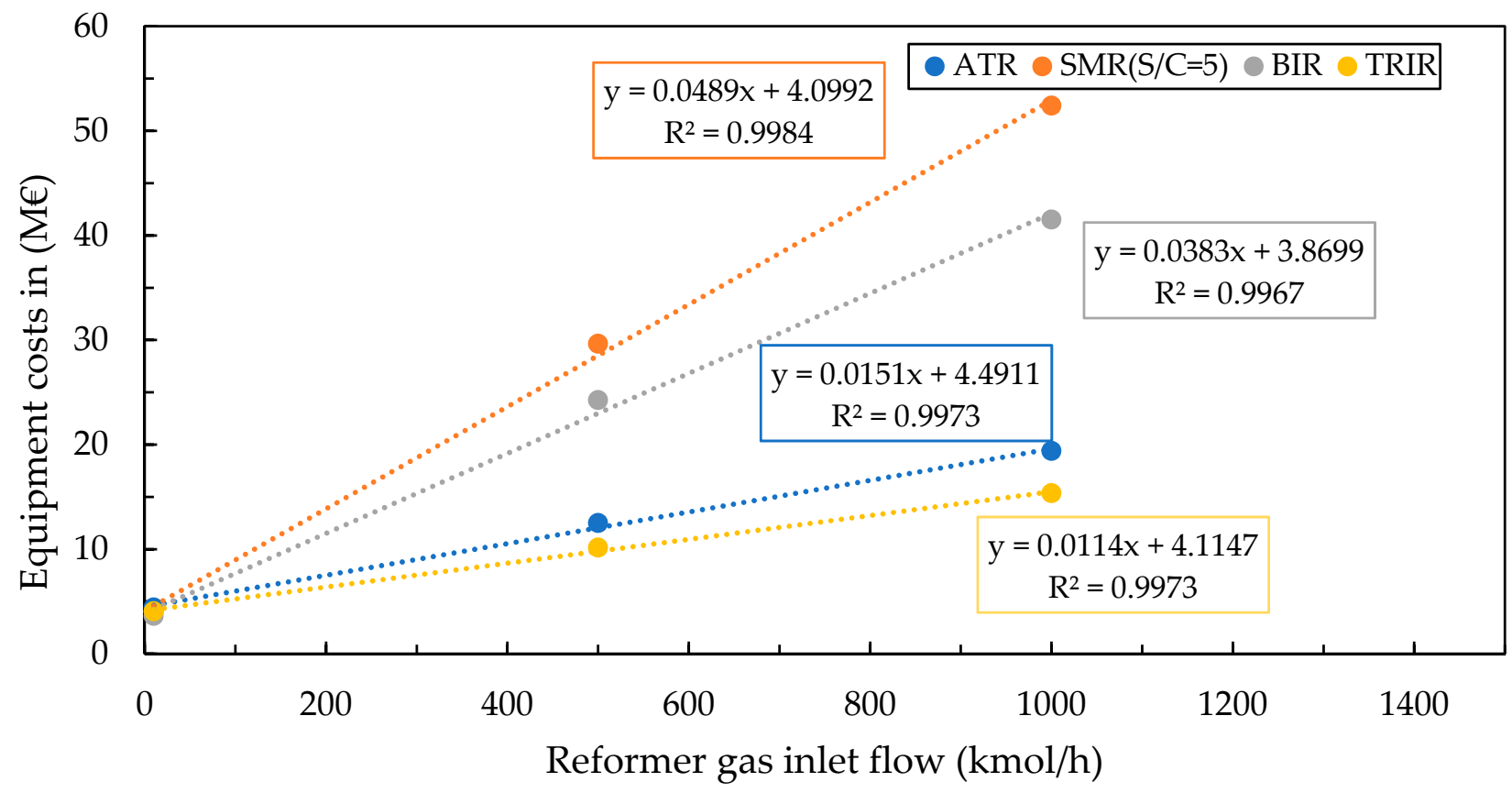

Figure 8. Economies of scale for total purchase equipment costs of $\mathrm{SMR}_{5}, \mathrm{ATR}, \mathrm{BIR}$ and TRIR.

The costs functions for the product compressor show, more or less, the same slope for all process designs. The reason for this is that there are similar flow rates and pressure changes in every design. However, it can be seen that the costs increase, depending on the $\mathrm{H}_{2}$ share in the product gas. This is due to the greater effort required to compress small molecules like $\mathrm{H}_{2}$ compared to larger molecules like $\mathrm{CO}_{2}$. 


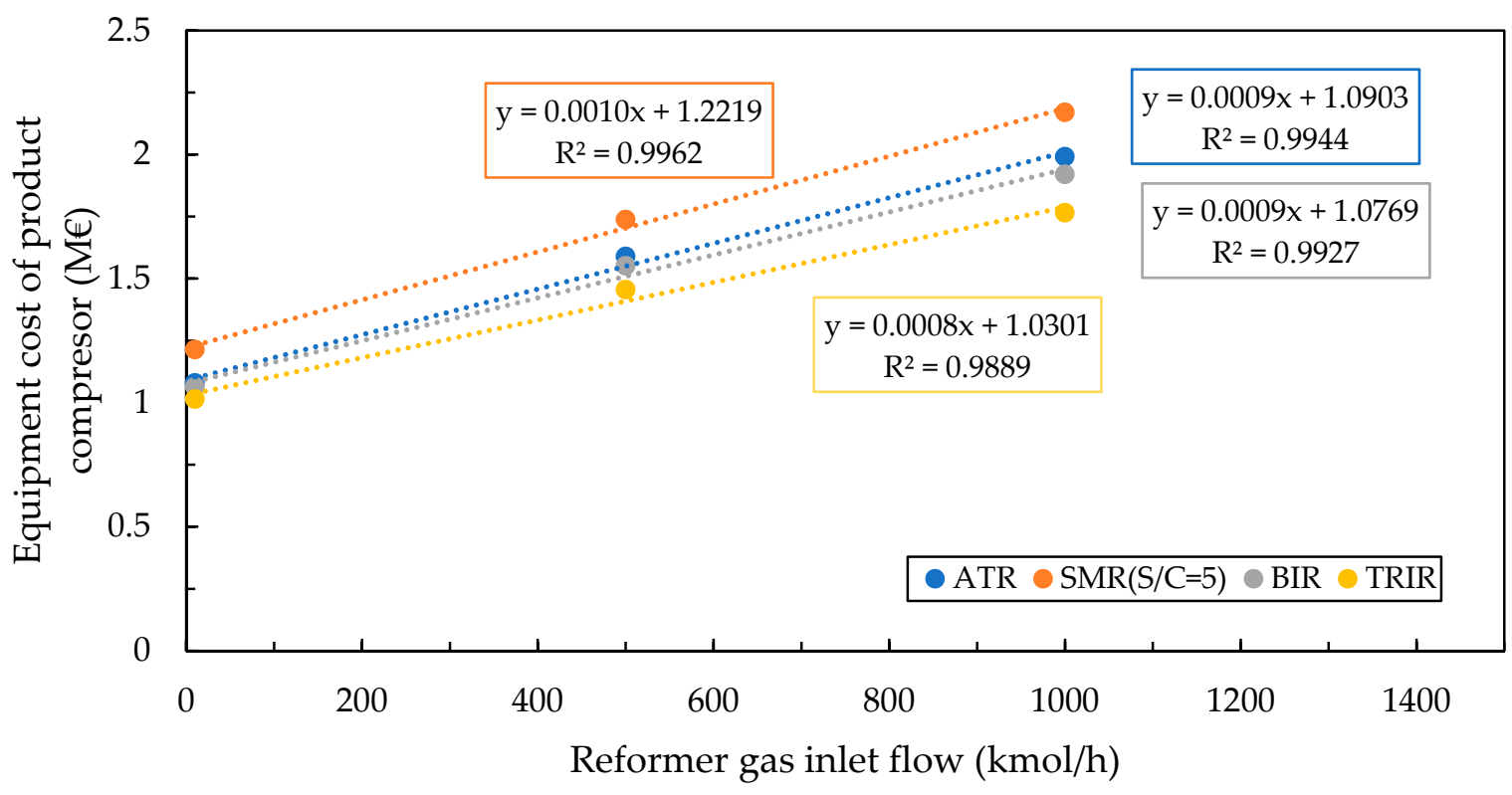

Figure 9. Economies of scale for product compressor from 22.2 bar to 70 bar.

\subsection{Process Performance Indicators of Selexol Process}

\subsubsection{Flow Characteristics}

$\mathrm{CO}_{2}$ capture using Selexol absorption is simulated for all the process concepts with a $\mathrm{CO}_{2}$ recovery factor of $90 \%$. Depending on the process (cf. Table 10), the cleaned product gas is mostly composed of $\mathrm{H}_{2}$ with molar shares of 93 to $96 \%$. In industry, $\mathrm{H}_{2}$ is often provided at ultra-high purities of $99.999 \%$. Therefore, the product gas has to be purified further using a pressure swing adsorption to generate ultra-pure $\mathrm{H}_{2}$ at $99.999 \%$ and an offgas containing the impurities, which can then be combusted for energy production.

Table 10. Clean gas output of Selexol process.

\begin{tabular}{cccccc}
\hline & ATR & SMR (S/C = 3.5) & TRIR & SMR (S/C = 5) & BIR \\
\hline $\mathrm{CO}$ (mole.- $\%)$ & 0.94 & 0.58 & 1.17 & 0.29 & 0.51 \\
$\mathrm{CO}_{2}$ (mole.- $\left.\%\right)$ & 03.14 & 2.21 & 4.88 & 2.22 & 3.47 \\
$\mathrm{H}_{2}$ (mole.- $\left.\%\right)$ & 95.53 & 94.44 & 93.54 & 96.20 & 94.78 \\
$\mathrm{H}_{2} \mathrm{O}$ (mole.- $\left.\%\right)$ & 0.07 & 0.07 & 0.07 & 0.07 & 0.07 \\
$\mathrm{CH}_{4}$ (mole.- $\left.\%\right)$ & 0.32 & 2.70 & 0.34 & 1.22 & 1.17 \\
\hline
\end{tabular}

The raw $\mathrm{CO}_{2}$ outlet flow from the Selexol process is provided at 1.95 bar and purities of 98 to 99 mass.-\% (cf. Table 11). It can be directly utilized, for example, in algae cultivation, or it can be further compressed and dehydrated to 150 bar for transport or storage. If compression is chosen, the purity is enhanced to 99.5 mass. $\%$ or higher due to dehydration.

Table 11. Raw $\mathrm{CO}_{2}$ out of Selexol process ( $\mathrm{p}=1.95$ bar).

\begin{tabular}{|c|c|c|c|c|c|}
\hline & ATR & SMR $(S / C=3.5)$ & TRIR & $\operatorname{SMR}(S / C=5)$ & BIR \\
\hline CO (mass.-\%) & 0.03 & 0.03 & 0.02 & 0.01 & 0.01 \\
\hline $\mathrm{CO}_{2}$ (mass.- $\%$ ) & 98.84 & 98.41 & 99.05 & 98.58 & 98.88 \\
\hline $\mathrm{H}_{2}$ (mass. $-\%$ ) & 0.06 & 0.09 & 0.03 & 0.09 & 0.05 \\
\hline $\mathrm{H}_{2} \mathrm{O}$ (mass.- $\%$ ) & 1.05 & 1.24 & 0.89 & 1.22 & 1.00 \\
\hline $\mathrm{CH}_{4}$ (mass.- $\left.\%\right)$ & 0.02 & 0.23 & 0.01 & 0.10 & 0.06 \\
\hline
\end{tabular}




\subsubsection{Equipment Costs and Economies of Scale}

As with the reforming processes, two additional sizes are simulated for this process. Just as for the reformer, the capacity is once halved and once reduced by the order of one hundred. Table 12 depicts the detailed purchase equipment costs of the Selexol process, as well as the potential $\mathrm{CO}_{2}$ compression for the input of $1000 \mathrm{kmol} / \mathrm{h}$ in the reformer gas feed. Figure 10 presents economy of scale graphs and functions for the different process inputs. The product gas from the SMR feed has the lowest $\mathrm{CO}_{2}$ concentration, while product gas from the TRIR process has the highest concentration. This directly affects the equipment costs, which increase with decreasing $\mathrm{CO}_{2}$ concentration.

Table 12. Equipment costs of Selexol process and $\mathrm{CO}_{2}$ compressor to 150 bar.

\begin{tabular}{cccccc}
\hline Feed Process & ATR & SMR (S/C = 3.5) & TRIR & SMR (S/C = 5) & BIR \\
\hline Equipment costs $€_{2018}$ & $5,181,794.00$ & $5,316,356.75$ & $3,811,979.50$ & $5,370.326 .25$ & $3,998,436.00$ \\
Equipment costs of compression $€_{2018}$ & $3,091,062.50$ & $2,796,847.50$ & $3,091,062.50$ & $2,816,792.75$ & $2,816,792.75$ \\
\hline
\end{tabular}

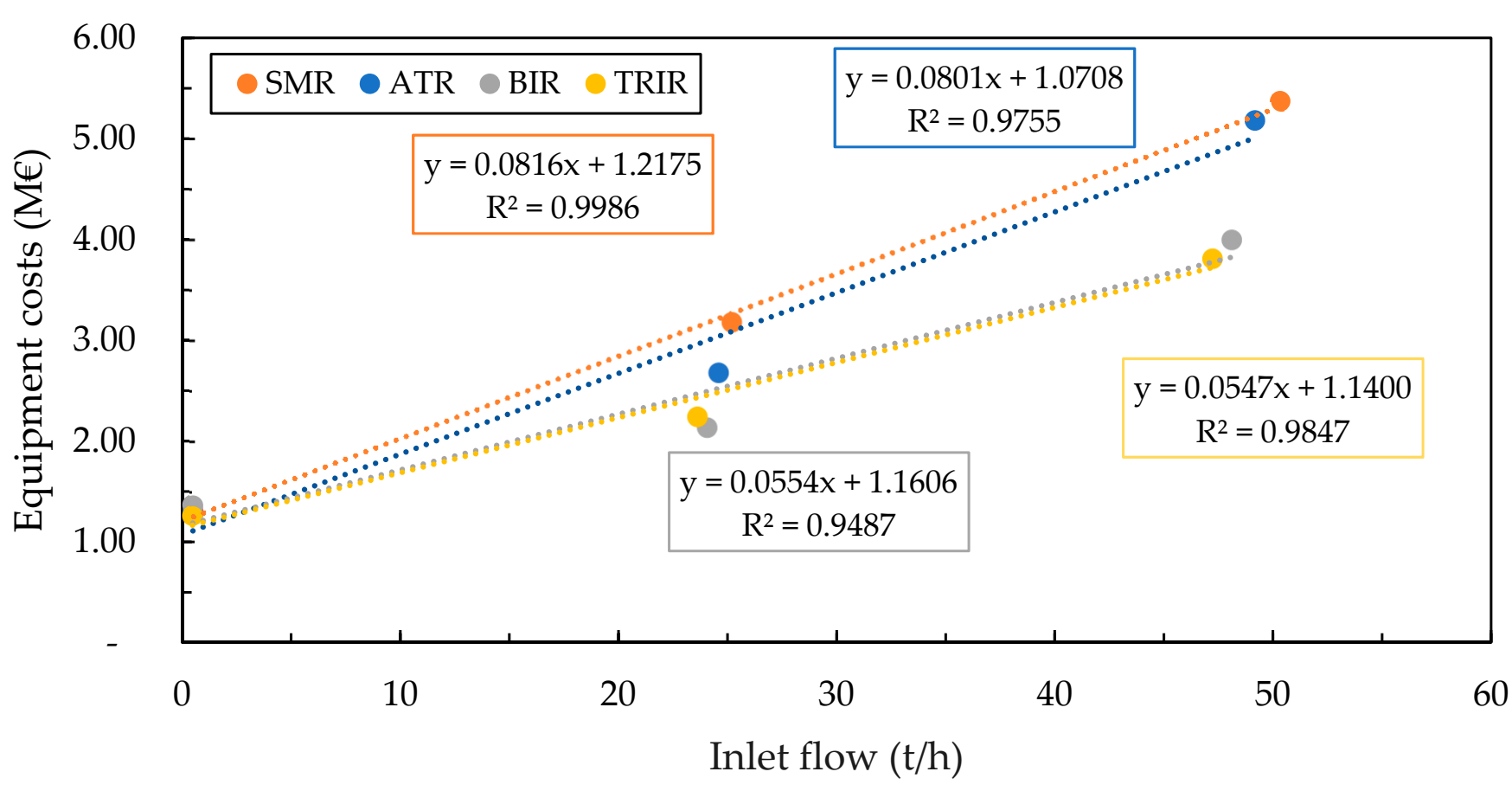

Figure 10. Economies of scale for Selexol process with different feed processes.

\subsubsection{Utility and Raw Material Demands}

The Selexol process requires different utilities, such as electricity, cooling water, refrigeration to $-1{ }^{\circ} \mathrm{C}$, make-up process water and fresh Selexol. The demand for the $\mathrm{CO}_{2}$ capture process (large capacity) is presented in Table 13. The correlation between $\mathrm{CO}_{2}$ concentration, utility and raw materials demand is similar to the correlation between $\mathrm{CO}_{2}$ concentration and equipment costs. A lower $\mathrm{CO}_{2}$ content leads to a higher demand of Selexol pump-around, which increases the demand of pumps, compressors, coolers and chillers. Table 14 presents the demand for the optional final $\mathrm{CO}_{2}$ compression. Here, waste water and flue gas are generated due to dehydration and the pressure release of waste streams. Waste water is nearly completely $(99.9 \%)$ composed of water, while flue gas is made up to $96 \%$ of $\mathrm{CO}_{2}$. 
Table 13. Utilities and raw materials demand for Selexol process with different feed processes.

\begin{tabular}{cccccc}
\hline & ATR & SMR (S/C = 3.5) & TRIR & SMR (S/C = 5) & BIR \\
\hline Electricity (MW) & 1.11 & 1.27 & 0.87 & 1.35 & 1.03 \\
Cooling water (MW) & 0.43 & 0.56 & 0.28 & 0.58 & 0.39 \\
Refrigeration (MW) & 1.64 & 1.70 & 0.96 & 1.78 & 1.24 \\
Make-up water (t/h) & 0.23 & 0.23 & 0.21 & 0.24 & 0.22 \\
Make-up Selexol (t/h) & 0.000009 & 0.000009 & 0.000008 & 0.00001 & 0.000008 \\
\hline
\end{tabular}

Table 14. Utilities and waste streams for $\mathrm{CO}_{2}$ compression from 1.95 to 150 bar.

\begin{tabular}{cccccc}
\hline & ATR & SMR (S/C = 3.5) & TRIR & SMR (S/C = 5) & BIR \\
\hline Electricity (MW) & 3.50 & 3.23 & 3.50 & 3.47 & 3.47 \\
Cooling water (MW) & 6.21 & 5.66 & 6.24 & 6.09 & 6.16 \\
Waste water (t/h) & 0.37 & 0.40 & 0.30 & 0.42 & 0.34 \\
Flue gas $(\mathrm{t} / \mathrm{h})$ & 0.0040 & 0.0041 & 0.0036 & 0.0043 & 0.0039 \\
\hline
\end{tabular}

\subsection{Techno-Economic Analysis}

For the techno-economic analysis, the net production costs of the produced SynFeed $\left(\mathrm{H}_{2} / \mathrm{CO}_{2}\right.$-rich mixture $)$ as well as the carbon capture costs per ton of product $\mathrm{CO}_{2}$ are calculated using the following approach.

First, the purchase equipment costs $\mathrm{EC}_{\mathrm{u}}$ of the major equipment $\mathrm{u}$ are obtained, based on the derived process performance indicators. Based on those raw costs, the fixed capital investment costs $\left(\mathrm{FCI}_{\mathrm{u}}\right)$ are calculated by multiplication with a cost factor, which includes direct costs like installation, electrics, buildings, service facilities or yard improvements, as well as indirect costs, such as engineering, contractor's fees and contingencies (ref. Equation (9)). In this work, the approach by Peters et al. [34] is followed, which yields cost accuracy of $\pm 30 \%$. The fixed capital investment is afterwards converted into annualized capital costs (ACC) by considering the capital recovery factor (CRF) based on the unitoperation lifetime (LT) and interest rate (IR) (ref. Equations (10) and (11)).

$$
\begin{gathered}
\mathrm{FCI}_{\mathrm{u}}[\mathrm{M} €]=\mathrm{EC}_{\mathrm{u}}[\mathrm{M} €] \cdot \mathrm{f}_{\mathrm{u}}^{\mathrm{I}}[-], \mathrm{u} \in \mathrm{Uu} \in \mathrm{U}, \mathrm{u} \in \mathrm{U} \\
\mathrm{ACC}\left[\frac{\mathrm{M} €}{\mathrm{y}}\right]=\sum_{\mathrm{u} \in \mathrm{U}} \mathrm{FCI}_{\mathrm{u}}[\mathrm{M} €] \cdot \mathrm{CRF}\left[\frac{1}{\mathrm{y}}\right], \mathrm{u} \in \mathrm{U} \\
\mathrm{CRF}\left[\frac{1}{\mathrm{y}}\right]=\frac{\mathrm{IR} \cdot(1+\mathrm{IR})^{\mathrm{LT}}}{(1+\mathrm{IR})^{\mathrm{LT}}-1}
\end{gathered}
$$

Operational costs include costs for utilities $\left(\mathrm{C}^{\mathrm{UT}}\right)$, such as electricity, cooling water or chilling energy, as well as raw materials $\left(\mathrm{C}^{\mathrm{RM}}\right)$, such as biogas feed or process water, and operating and maintenance costs (ref. Equation (15)). Utility ut and raw material i costs are derived by calculating their hourly demand multiplied by operating hours per year $(\mathrm{H})$, as well as the specific costs per ton (of raw material) or MWh (of utility) as depicted in Equations (12) and (13). Operating and maintenance costs $\left(\mathrm{C}^{\mathrm{O} \& \mathrm{M}}\right)$ are derived by a factor of $4 \%$ of fixed capital investment, as shown in Equation (14).

$$
\begin{gathered}
\mathrm{C}^{\mathrm{UT}}\left[\frac{€}{\mathrm{y}}\right]=\sum_{\text {ut } \in \mathrm{UT}} \mathrm{D}_{\mathrm{ut}}[\mathrm{MW}] \cdot \mathrm{H}\left[\frac{\mathrm{h}}{\mathrm{y}}\right] \cdot \mathrm{c}_{\mathrm{ut}}\left[\frac{€}{\mathrm{MWh}}\right] \\
\mathrm{C}^{\mathrm{RM}}\left[\frac{€}{\mathrm{y}}\right]=\sum_{\mathrm{i} \in \mathrm{I}} \mathrm{D}_{\mathrm{i}}\left[\frac{\mathrm{t}}{\mathrm{h}}\right] \cdot \mathrm{c}_{\mathrm{i}}\left[\frac{€}{\mathrm{t}}\right] \cdot \mathrm{H}\left[\frac{\mathrm{h}}{\mathrm{y}}\right] \\
\mathrm{C}^{\mathrm{O} \& \mathrm{M}}\left[\frac{\mathrm{M} €}{\mathrm{y}}\right]=\mathrm{f}^{\mathrm{O} \& \mathrm{M}}\left[\frac{1}{\mathrm{y}}\right] \cdot \mathrm{FCI}[\mathrm{M} €]
\end{gathered}
$$


Annualized operating costs (AOC) and annualized capital costs form the total annualized costs (TAC), which are divided by the produced product (total SynFeed or captured $\mathrm{CO}_{2}$ ) to calculate the net production costs (NPC) (ref. Equations (15)-(17)).

$$
\begin{gathered}
\mathrm{AOC}\left[\frac{\mathrm{M} €}{\mathrm{a}}\right]=\left(\mathrm{C}^{\mathrm{UT}}+\mathrm{C}^{\mathrm{RM}}\right) \cdot 10^{6}+\mathrm{C}^{\mathrm{O} \& \mathrm{M}} \\
\mathrm{TAC}\left[\frac{\mathrm{M} €}{\mathrm{a}}\right]=\mathrm{ACC}+\mathrm{AOC} \\
\mathrm{NPC}\left[\frac{€}{\mathrm{t}}\right]=\frac{\mathrm{TAC}\left[\frac{\mathrm{M} €}{\mathrm{a}}\right]}{\mathrm{F}^{\mathrm{PROD}}\left[\frac{\mathrm{Mt}}{\mathrm{a}}\right]}
\end{gathered}
$$

\subsubsection{Economic Assumptions}

General assumptions regarding the economic data are presented in Table 15. These include plant lifetime and interest rate, as well as specific utility and raw material costs.

Table 15. Key parameters for techno-economic analysis [17,30,33-36].

\begin{tabular}{cccc}
\hline Parameter & Value & Parameter & Value \\
\hline Lifetime LT & $25 \mathrm{y}$ & Costs for oxygen & $26.3 € / \mathrm{t}$ \\
Interest rate IR & $5 \%$ & Maintenance cost factor f & 0.04 \\
Costs for electricity & $87 € / \mathrm{MWh}$ & Costs for fresh Selexol & $6500 € / \mathrm{t}$ \\
Costs for cooling water & $0.22 € / \mathrm{MWh}$ & Costs for process water & $0.075 € / \mathrm{t}$ \\
Costs for steam & $48.6 € / \mathrm{MWh}$ & Costs for refrigerant energy & $25.56 € / \mathrm{MWh}$ \\
Fixed capital investment cost factor $\mathrm{f}_{\mathbf{u}}^{\mathrm{I}}$ & 5.04 & Operating hours $\mathrm{H}$ & $8260 \mathrm{~h} / \mathrm{y}$ \\
Waste water & $2 € / \mathrm{t}$ & Additional CO 2 & $50 € / \mathrm{t}$ \\
Costs for biogas & $350 € / \mathrm{t}$ & Additional $\mathrm{H}_{2}$ & $3500 € / \mathrm{t}$ \\
Costs of biogas purification (ref. & $24.2 € / \mathrm{t}_{\mathrm{CH}_{4}}$ & Costs of $\mathrm{H}_{2}$ separation (including PSA & $715 € / \mathrm{t}_{\mathrm{H}_{2}}$ \\
Appendix B) & + Compression from ambient to 22.2 & bar) ref. Appendix C \\
Costs for upgraded & $11.36 € / \mathrm{t}$ & &
\end{tabular}

\subsubsection{Costs of Raw SynFeed}

Table 16 shows the calculated annualized operating and capital costs, total annualized costs, yearly output flow of raw SynFeed, $\mathrm{H}_{2} / \mathrm{CO}_{2}$ ratio and the net production costs per ton of raw SynFeed. A first look suggests that autothermal reforming is the most cost-efficient process and bi-reforming of raw biogas is the most expensive one. However, considering the varying $\mathrm{H}_{2} / \mathrm{CO}_{2}$ ratios, it is apparent that the quality of the raw SynFeed is different. None of the produced stream shows a molar ration 3. SMR has excess $\mathrm{H}_{2}$, while the other process types produce SynFeed with excess $\mathrm{CO}_{2}$. In order to improve the SynFeed in terms of methanol production and form a fair basis for comparison with SynFeed, upgrading is considered. This upgrading consists of either the capture excess $\mathrm{CO}_{2}\left(\mathrm{H}_{2}\right)$ or mixing additional $\mathrm{H}_{2}\left(\mathrm{CO}_{2}\right)$. However, in order to calculate $\mathrm{CO}_{2}$ capture for SynFeed upgrading, the capture costs using the Selexol process have to first be investigated.

Table 16. Cost results for different reforming technologies (Case of $1000 \mathrm{kmol} / \mathrm{h}$ reformer gas input).

\begin{tabular}{ccccc}
\hline & SMR $(\mathbf{S} / \mathbf{C}=\mathbf{5})$ & BIR & TRIR & ATR \\
\hline ACC $\left(€_{2018} / y\right)$ & $19,513,992$ & $15,528,909$ & $6,116,062$ & $7,646,924$ \\
AOC $\left(\epsilon_{2018} / y\right)$ & $92,548,893$ & $137,896,870$ & $86,728,071$ & $65,089,406$ \\
TAC $\left(€_{2018} / y\right)$ & $112,062,885$ & $153,425,779$ & $92,844,134$ & $72,736,331$ \\
Output flow $(\mathrm{t} / \mathrm{y})$ & 415,678 & 396,976 & 389,716 & 405,694 \\
$\mathrm{H}_{2} / \mathrm{CO}_{2}$ & 3.99 & 2.54 & 1.78 & 2.81 \\
$\mathrm{NPC}_{\text {SynFeed }}(€ / \mathrm{t})$ & 269.59 & 386.49 & 238.24 & 179.29 \\
\hline
\end{tabular}




\subsubsection{Carbon Capture Costs}

Table 17 presents the costs of $\mathrm{CO}_{2}$ capture using the simulated Selexol process. It is possible to utilize $\mathrm{CO}_{2}$ at low pressures in an algae refinery. Therefore, the costs for compression to 150 bar are displayed separately. The correlations between utility demand, capital expenditures and $\mathrm{CO}_{2}$ content in the feed gas of the Selexol process lead to the lowest carbon capture costs of $22.6 € / t$ for SynFeed from TRIR, if $\mathrm{CO}_{2}$ is to be compressed to $150 \mathrm{bar}$. The highest carbon capture costs are detected for the SMR process, with $27.2 € / \mathrm{t}$. For all processes it is observed that the $\mathrm{CO}_{2}$ compression makes up about $50-60 \%$ of the total carbon capture costs. Therefore, it would be beneficial to utilize $\mathrm{CO}_{2}$ at low pressures on-site, reducing the carbon capture costs to $9-14 € / \mathrm{t}$. Compared to other $\mathrm{CO}_{2}$ capture technologies, such as pressure swing adsorption or MEA capture, Selexol is identified as a cost competitive option for biogas reforming feed.

Table 17. Carbon capture costs for large scale raw SynFeed.

\begin{tabular}{|c|c|c|c|c|}
\hline & $\operatorname{SMR}(S / C=5)$ & BIR & TRIR & ATR \\
\hline $\mathrm{AOC}_{\mathrm{CC}}\left(€_{2018}\right)$ & $2,433,859$ & $1,815,080$ & $1,604,584$ & $2,193,631$ \\
\hline $\mathrm{ACC}_{\mathrm{CC}}\left(€_{2018}\right)$ & $1,920,431$ & $1,429,842$ & $1,363,165$ & $1,853,012$ \\
\hline $\mathrm{TAC}_{\mathrm{CC}}\left(€_{2018}\right)$ & $4,354,290$ & $3,244,922$ & $2,967,749$ & $4,046,643$ \\
\hline $\mathrm{AOC}_{\mathrm{CO} 2-\mathrm{Comp} .}\left(€_{2018}\right)$ & $3,075,935$ & $3,080,506$ & $3,156,825$ & $3,157,080$ \\
\hline ACC $C$ C2-Comp. $\left(€_{2018}\right)$ & $1,007,286$ & $1,007,286$ & $1,105,365$ & $1,105,365$ \\
\hline TAC ${ }_{\text {CO2-Comp. }}\left(€_{2018}\right)$ & $4,083,221$ & $4,087,793$ & $4,262,190$ & $4,262,445$ \\
\hline $\mathrm{CO}_{2}$ outlet flow $(\mathrm{t} / \mathrm{y})$ & 310,305 & 315,136 & 320,131 & 317,238 \\
\hline Carbon Capture Costs $\left(€ / \mathrm{t}_{\mathrm{CO}_{2}}\right)$ & 14.03 & 10.30 & 9.27 & 12.76 \\
\hline Compression costs $\left(€ / \mathrm{t}_{\mathrm{CO}_{2}}\right)$ & 13.16 & 12.97 & 13.31 & 13.44 \\
\hline Total costs $\left(€ / \mathrm{t}_{\mathrm{CO}_{2}}\right)$ & 27.19 & 23.27 & 22.58 & 26.19 \\
\hline
\end{tabular}

\subsubsection{Cost of Adjusted SynFeed}

As already indicated, the different raw SynFeed streams are not on specification for methanol synthesis in regard to their $\mathrm{H}_{2} / \mathrm{CO}_{2}$. To provide a fair comparison, the raw SynFeed is conditioned to specifications by either $\mathrm{H}_{2}$ separation, $\mathrm{CO}_{2}$ addition (in the case of SMR), $\mathrm{CO}_{2}$ separation or $\mathrm{H}_{2}$ addition (for all other cases). Additional educts are priced by costs relating to $\mathrm{CO}_{2}$ from flue gas capture using MEA $\left(50 / \mathrm{t}_{\mathrm{CO}_{2}}\right)$ and $\mathrm{H}_{2}$ from water electrolysis $\left(3500 € / \mathrm{t}_{\mathrm{H}_{2}}\right.$ ). Separation of excess $\mathrm{CO}_{2}$ is achieved through partial $\mathrm{CO}_{2}$ capture using the simulated Selexol process. Here, linear dependent utility and raw material demands as well as the presented economies of scale are used to calculate the additional costs of partial separation. $\mathrm{No} \mathrm{CO}_{2}$ compression is considered in this case. In the case of $\mathrm{H}_{2}$ excess, $\mathrm{H}_{2}$ separation is calculated by pressure swing adsorption based on Spallina et al. [30]. Using PSA, pure $\mathrm{H}_{2}$ is produced at feed pressures (22.2 bar), while the remaining SynFeed is depressurized to vacuum pressures. The PSA-train is simulated using Aspen Plus. Here, the PSA itself is modeled as a black-box component separator with a $\mathrm{H}_{2}$ recovery factor of $89 \%$ (further information can be found in Appendix C) [30]. SynFeed is afterwards repressurized by a vacuum pump to 22.2 bar. For all conditioned SynFeed streams an additional product compressor, supplying pressurization from $22.2 \mathrm{bar}$ to $70 \mathrm{bar}$, is implemented (further information can be found in Appendix A). This way, the costs for capital expenditures and energy for the initial product compressor are adjusted to the new $\mathrm{H}_{2} / \mathrm{CO}_{2}$ ratio. In the case of separation, the byproducts $\left(\mathrm{CO}_{2}\right.$ or $\left.\mathrm{H}_{2}\right)$ are assumed to be used on-site and replace additional production by either MEA carbon capture or water electrolysis, leading to additional accounted revenues.

Table 18 shows the results of the SynFeed conditioning. If byproducts can be utilized on-site, SMR is the most economical process with NPC of $142.5 € / t_{\text {SynFeed, }}$ followed by ATR with $167.7 € / \mathrm{t}_{\text {SynFeed. }}$. However, if, for example, pure $\mathrm{H}_{2}$ and $\mathrm{CO}_{2}$ are not required, and it is not possible to gain revenue for these products, it is beneficial to use ATR when combined with additional $\mathrm{CO}_{2}$ capture at NPC of $197.4 € / \mathrm{t}_{\text {SynFeed }}$. 
Table 18. Mass flows and net production costs of conditioned SynFeed.

\begin{tabular}{ccccc}
\hline & SMR & BIR & TRIR & ATR \\
\hline & Mixing & Conditioning & & \\
Additional $\mathrm{CO}_{2}(\mathrm{t} / \mathrm{y})$ & 118,848 & 0 & 0 & 0 \\
Additional $\mathrm{H}_{2}(\mathrm{t} / \mathrm{y})$ & 0 & 6793 & 19,462 & 2221 \\
$\mathrm{NPC}_{\text {Tot. }}\left(€ / \mathrm{t}_{\mathrm{SynFeed}}\right)$ & 220.77 & 438.87 & 393.37 & 197.37 \\
& Separation Conditioning & & \\
Separated $\mathrm{H}_{2}(\mathrm{t} / \mathrm{y})$ & 15,637 & & & \\
Separated $\mathrm{CO}_{2}(\mathrm{t} / \mathrm{y})$ & & 50,320 & 144,106 & 16,452 \\
$\mathrm{NPC}_{\text {Tot. }}\left(€ / \mathrm{t}_{\text {SynFeed }}\right)$ & 142.48 & 413.44 & 330.38 & 165.71 \\
\hline
\end{tabular}

If SynFeed from biogas reforming is compared to a SynFeed mixture prepared by $\mathrm{CO}_{2}$ capture from flue gas and water electrolysis, it shows significantly lower costs of $142-438 € / \mathrm{t}_{\text {SynFeed }}$ compared with $464 € / \mathrm{t}_{\text {SynFeed }}$ (further information in Appendix D). If SynFeed from biogas is compared to SynFeed from natural gas, it shows a higher cost of $142-438 € / \mathrm{t}_{\text {SynFeed }}$ compared with $107-177 € / \mathrm{t}_{\text {SynFeed }}$, depending on the utilization of byproducts. Regardless of the case, it is always more economical to separate $\mathrm{CO}_{2}$ from the raw biogas before processing, due to low purification costs of $24.2 € / t_{\mathrm{CH}_{4}}$ based on the values described in the literature.

\subsubsection{Sensitivity Analysis}

In all biogas upgrading concepts presented, the operational costs significantly outweigh the capital costs. The biggest proportion of costs is comprised of the raw material costs for the biogas, which represent about 75 to $95 \%$ of the operating costs. Since biogas costs from algae remnant treatment are rarely discussed in the literature, these were approximated at 5.5 to $6.5 \mathrm{ct} / \mathrm{kWh}$ from conventional biogas production in Germany [36]. The results reveal that SynFeed generated from such biogas is cost competitive in relation to SynFeed that is purely produced by water electrolysis and $\mathrm{CO}_{2}$ capture, however, it is not competitive with SynFeed generated from natural gas. To show the effect of biogas costs on the total costs of SynFeed, Figures 11 and 12 depicts the costs for adjusted SynFeed by either mixing or separation conditions depending on the raw biogas costs. First, it can be seen that direct biogas reforming systems (BIR, TRIR) show steeper gradients and therefore a higher dependency. While they are not competitive at present costs, this could change if biogas becomes cheaper in the future. Secondly, even with high biogas costs, SMR and ATR are still cheaper than solely producing SynFeed with electrolysis and $\mathrm{CO}_{2}$ capture. However, a break-even can be assumed at biogas costs around $1000 € /$ t. Lastly, Figures 11 and 12 show that, for lower biogas costs at around $300 € / t$, biogas reforming is even cheaper than utilizing natural gas.

\subsubsection{Biogas Reforming as a Precursor for Integrated Algae Biorefineries}

This techno-economic analysis reveals that SMR and ATR processes are the most economic options. The considered capacity is in the order of the algae refinery described by Klein-Marcuschamer et al., with an output of $46 \mathrm{kt}$ of jet fuel [28]. The hydro-processing step of this refinery requires $15 \mathrm{kt} / \mathrm{y}$ of $\mathrm{H}_{2}$. By implementing the SMR process for biogas upgrading, $16 \mathrm{kt} / \mathrm{y}$ of $\mathrm{H}_{2}$ and $400 \mathrm{kt} / \mathrm{y}$ of SynFeed are produced. In an integrated refinery, the produced $\mathrm{H}_{2}$ could satisfy the hydro-processing demand, while the SynFeed could be converted to $250 \mathrm{kt} / \mathrm{y}$ of methanol. The methanol, in turn, could be further processed to $50 \mathrm{kt} / \mathrm{y}$ of jet fuel with diesel, gasoline and LPG as byproducts, using Lurgi's MtSynfuels process $[37,38]$. This would double the capacity of the algae refinery and substitute about $320 \mathrm{MW}$ electrolyser capacity, compared to an electricity-based approach [39]. If the ATR case is considered, about $16 \mathrm{kt} / \mathrm{y}$ of $\mathrm{CO}_{2}$ is produced, which corresponds to $1.4 \%$ of the total $\mathrm{CO}_{2}$ input of the algae refinery. Additionally, about $390 \mathrm{kt} / \mathrm{y}$ of SynFeed is generated, which could supply about $240 \mathrm{kt} / \mathrm{y}$ of methanol. In this case, the $\mathrm{H}_{2}$ in the algae oil hydro-processing has to be generated by a $100 \mathrm{MW}$ electrolyser, which would also generate 
about $80 \%$ of the oxygen demand of the ATR process. It is evident that steam methane or autothermal reforming of arising biogas in an algae refinery can be a valuable tool to integrate different concepts and increase product output and economic feasibility.

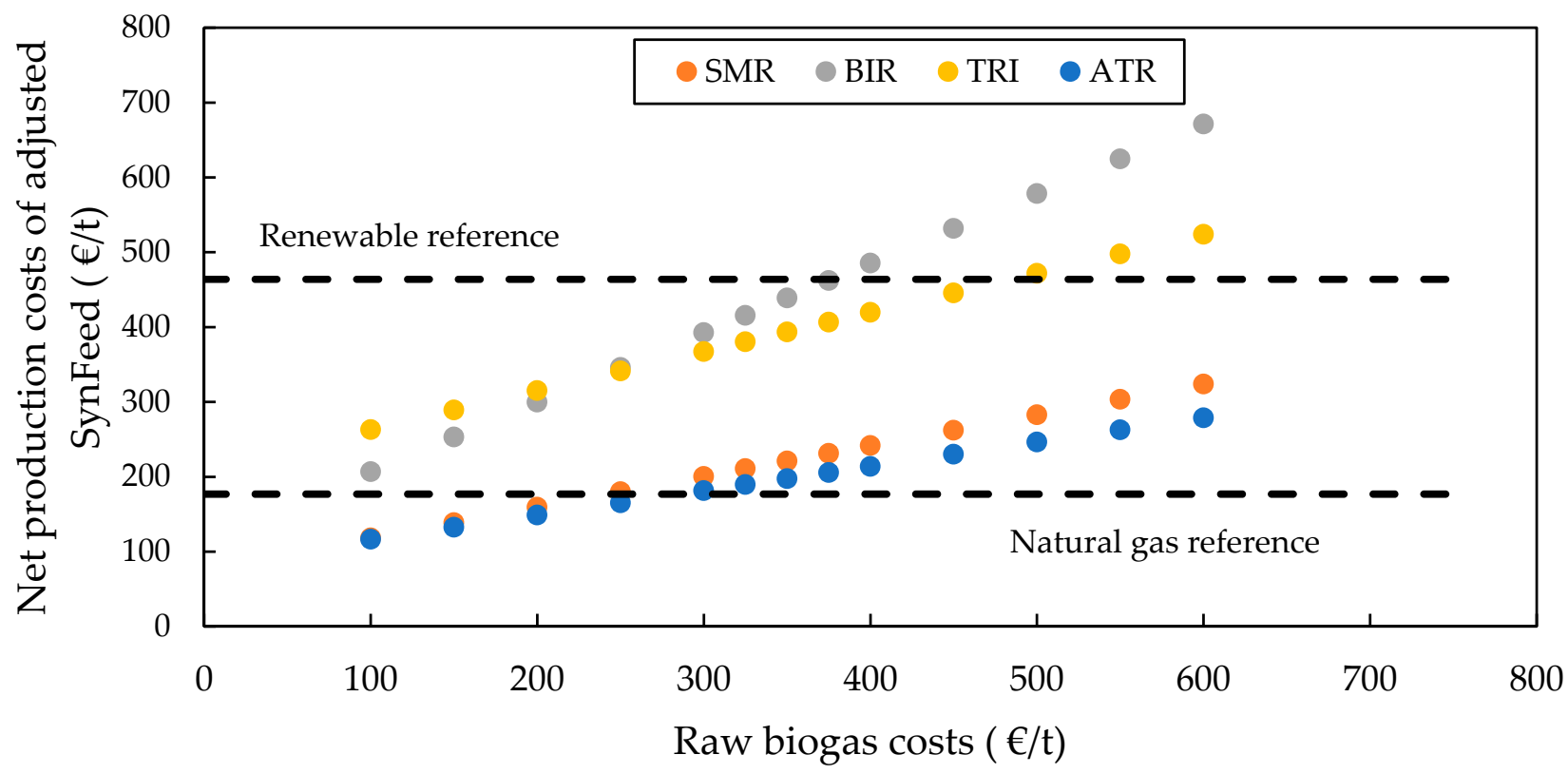

Figure 11. Net production costs of adjusted SynFeed for different raw biogas costs for mixing conditions.

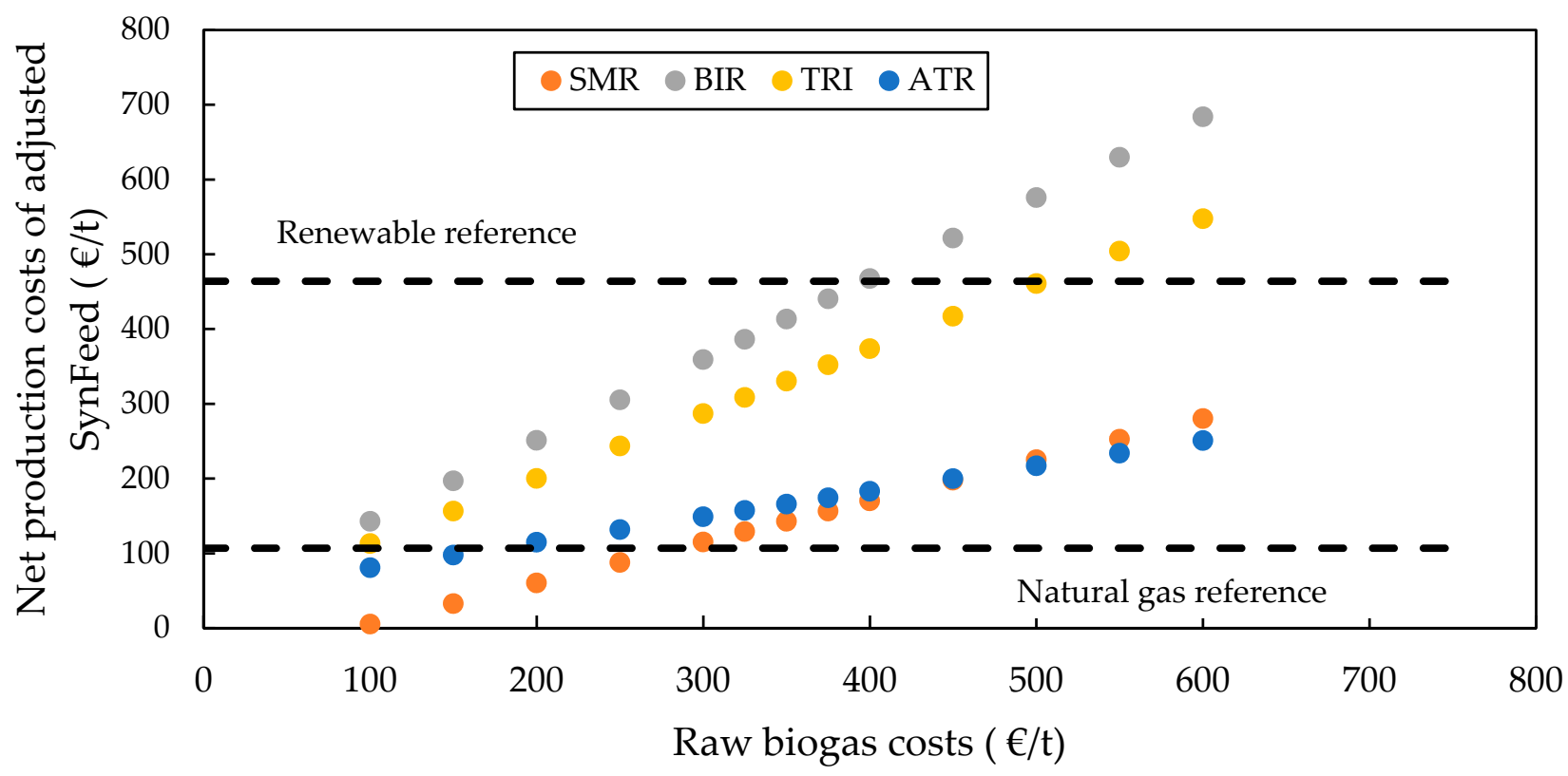

Figure 12. Net production costs of adjusted SynFeed for different raw biogas costs for separation conditions.

\section{Conclusions}

This study presents a detailed simulation and techno-economic assessment of different biogas reforming processes for the production of $\mathrm{H}_{2} / \mathrm{CO}_{2}$ (SynFeed) as a precursor for methanol synthesis, as well as carbon capture from the obtained product using the Selexol process. The results show, that biogas reforming to SynFeed can be economical superior to electricity-based SynFeed produced from water electrolysis and carbon capture units. Especially in algae-based biorefineries, where methanol as well as $\mathrm{H}_{2}$ and $\mathrm{CO}_{2}$ are chemical intermediates for transesterification, hydro-processing and algae growth, this concept shows great potential for creating a circular economy. Biogas reforming offers the potential 
to convert low value-added gas into higher value-added components which could, in turn, lead to a self-sufficient production of algae-based biodiesel or biokerosene. However, costs of biogas reforming are strongly dependent on variety of parameters, such as electricity costs, oxygen availability or raw biogas production costs. Based on the presented process performance indicators and techno-economic key figures, a more integrated approach on algae-based biorefineries should be investigated. In such an integrated concept, the whole algae-processing chain should be implemented, and different biogas processing options compared and discussed in the context of an overall production of biodiesel or biokerosene.

Author Contributions: Conceptualization, P.K. and T.W.; methodology, P.K.; software, P.K.; validation, P.K. and T.W.; formal analysis, P.K.; investigation, P.K.; data curation, P.K. and T.W.; writingoriginal draft preparation, P.K.; writing-review and editing T.W. and E.Z.; visualization, P.K.; supervision, T.W. and E.Z.; project administration, T.W.; funding acquisition, T.W. All authors have read and agreed to the published version of the manuscript.

Funding: Funding of this research by the German Federal Ministry of Economic Affairs and Energy within the KEROSyN100 project (funding code 03EIV051A) is gratefully acknowledged.

Institutional Review Board Statement: Not applicable.

Informed Consent Statement: Not applicable.

Conflicts of Interest: The authors declare no conflict of interest. The funders had no role in the design of the study; in the collection, analyses, or interpretation of data; in the writing of the manuscript, or in the decision to publish the results.

\section{Appendix A}

For the techno-economic analysis, the normal process integrated compressor is neglected for the cases where partial product separation is considered. This is due to the fact that the elevated raw SynFeed is used in the process of $\mathrm{CO}_{2} / \mathrm{H}_{2}$ separation. However, after the capture process, all streams are again compressed to 70 bar to be on spec for methanol synthesis. This is done through the use of additional calculated compressors for upgraded SynFeed. Because all SynFeed streams have the same $\mathrm{H}_{2} / \mathrm{CO}_{2}$ ratio with low amounts of impurities, the compression can be calculated using data for only one compressor. Figure A1 shows the economies of scale data for this compressor.

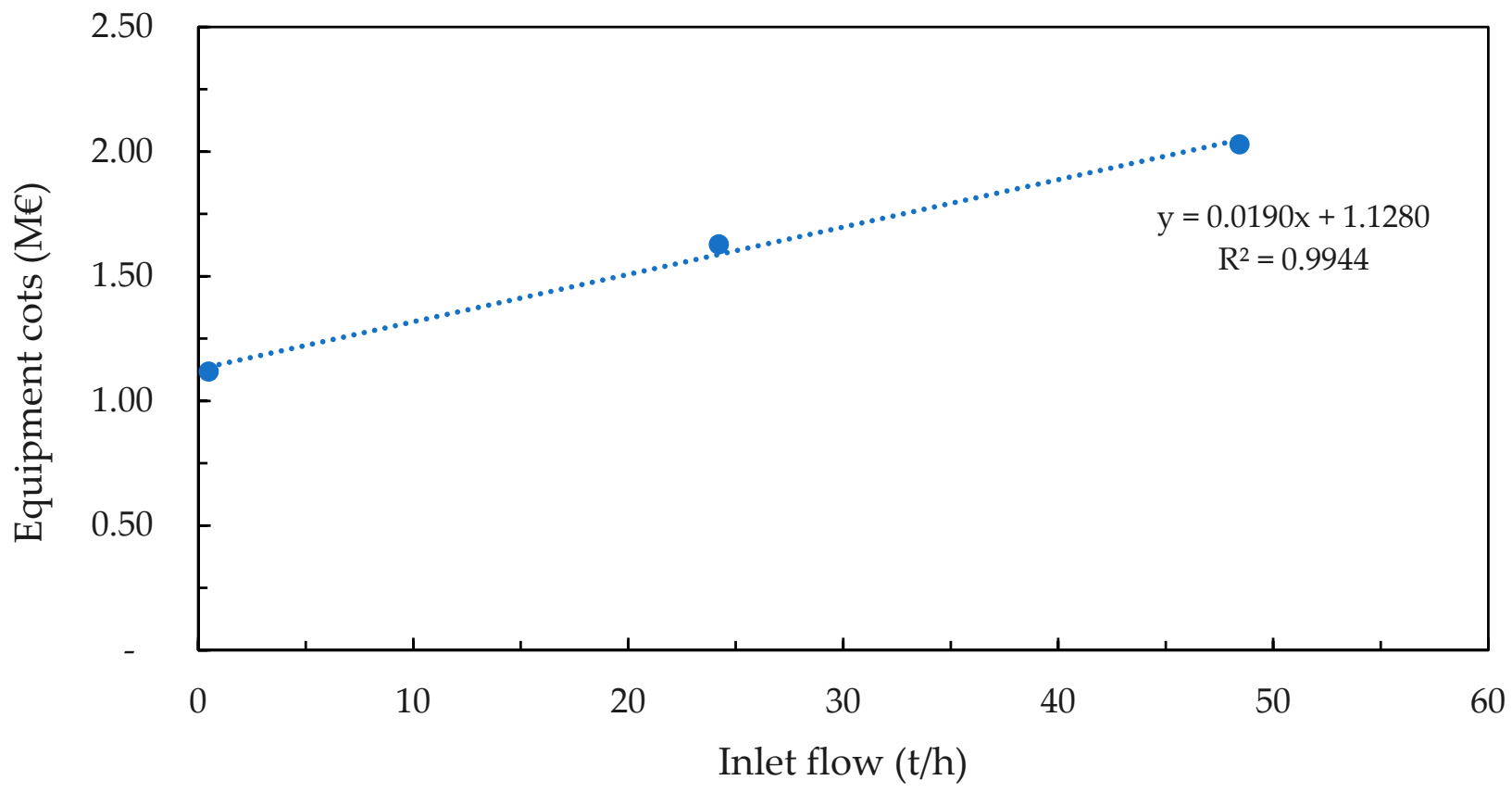

Figure A1. Equipment cost function for compressor of upgraded SynFeed $\left(\mathrm{H}_{2} / \mathrm{CO}_{2}=3\right)$ from 0.9 bar to 22.2 bar. 
For the $\mathrm{H}_{2}$ separation in the SMR-case, a pressure swing adsorption adopted from Spallina et al. is implemented [30]. While the PSA is only modelled as a black box component separator, the required vacuum pump is simulated in detail using Aspen Plus (and its economic analyzer). The whole train, consisting of the PSA, vacuum pump and compression to 22.2 bar (feed for the upgraded product compressor) is lumped together to create one unit-equipment. The capital costs and economies of scale for the PSA train are depicted in Figure A2.

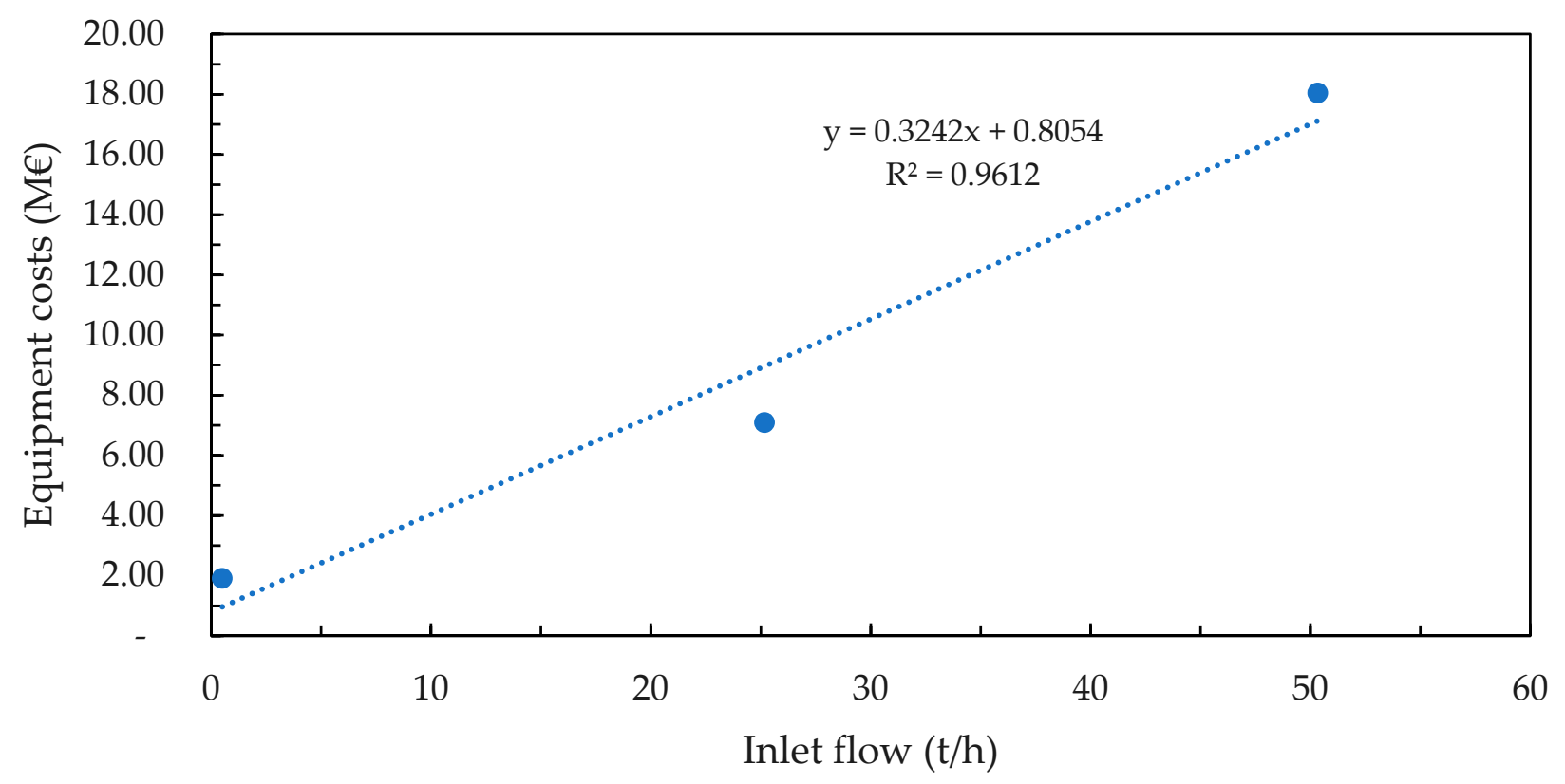

Figure A2. PSA train equipment costs (including PSA and vacuum pump + compression of upgraded SynFeed to 22.2 bar).

\section{Appendix B}

For pure methane reforming (SMR and ATR), $\mathrm{CO}_{2}$ has to first be separated from the raw biogas. Biogas is normally available at ambient pressures, which makes it generally unsuitable for the simulated Selexol process. In reality, upgrading biogas to biomethane is often achieved by $\mathrm{CO}_{2}$ capture using pressure swing adsorption. The costs for biomethane production are adopted from Gong et al. [17]. Here, the same approach which includes a techno-economic analysis is taken. Capital costs are derived from economies of scale and values described in the literature. Utility costs are derived from the costs of electricity. Capital costs, as well as electricity costs, are dependent on capturing the mass flow of $\mathrm{CO}_{2}$ (CCFR). Therefore, the first $1000 \mathrm{kmol} / \mathrm{h}$ of raw biogas is converted into mass flows of $\mathrm{CH}_{4}$ and $\mathrm{CO}_{2}$, based on a molar ratio of $0.65 / 0.35$ (ref. Equations (A1)-(A3)). Afterwards, the raw equipment costs are derived using economies of scale $((\mathrm{A} 5)+(\mathrm{A} 6))$ and the annualized costs (ACC) are calculated by using the approach depicted in the techno-economic analysis (A7). Electricity costs are calculated by using the specific electricity demand per ton of $\mathrm{CO}_{2}$ for the vacuum pump (A8) and costs for electricity of $87 € / \mathrm{MWh}$, while operating hours are assumed to be $8260 \mathrm{~h} / \mathrm{y}$ (A9). Finally, the costs per ton of upgraded $\mathrm{CH}_{4}$ or captured $\mathrm{CO}_{2}$ are derived by dividing costs by the mass flows ((A10-(A12)).

$$
\begin{gathered}
1000 \frac{\mathrm{kmol}}{\mathrm{h}} \text { Biogas }=650 \frac{\mathrm{kmol}}{\mathrm{h}} \mathrm{CH}_{4}+350 \frac{\mathrm{kmol}}{\mathrm{h}} \mathrm{CO}_{2} \\
650 \frac{\mathrm{kmol}}{\mathrm{h}} \cdot 16 \frac{\mathrm{kg}}{\mathrm{kmol}}=10.4 \frac{\mathrm{t}}{\mathrm{h}} \mathrm{CH}_{4} \\
350 \frac{\mathrm{kmol}}{\mathrm{h}} \cdot 44 \frac{\mathrm{kg}}{\mathrm{kmol}}=15.4 \frac{\mathrm{t}}{\mathrm{h}} \mathrm{CO}_{2}
\end{gathered}
$$




$$
\begin{gathered}
\mathrm{CCFR}=15.4 \frac{\mathrm{t}}{\mathrm{h}} \mathrm{CO}_{2} \\
\mathrm{EC}_{\mathrm{PSA}_{-} \mathrm{CO}_{2}}=3.73 \cdot\left(\frac{\mathrm{CCFR}}{15.84}\right)^{0.6} \cdot \frac{603.1}{567.7} \cdot 0.90 \frac{€}{\$} \\
\mathrm{EC}_{\mathrm{PSA}_{-} \mathrm{CO}_{2}}=3.505 \mathrm{M} € \\
\mathrm{ACC} \mathrm{PSA}_{-} \mathrm{CO}_{2}=1.302 \mathrm{M} € \\
\mathrm{el}=0.070 \mathrm{MWh} / \mathrm{t}_{\mathrm{CO}_{2}} \\
\mathrm{EL}=\mathrm{el} \cdot \mathrm{CCFR} \cdot \mathrm{C}_{\mathrm{el}} \cdot 8260 \mathrm{~h}=8415.5 \mathrm{MWh} \cdot 87 \frac{€}{\mathrm{MWh}}=0.73 \mathrm{M€} \\
\mathrm{CH} 4 \mathrm{FR}=10.4 \frac{\mathrm{t}}{\mathrm{h}} \mathrm{CH} \cdot 8260 \mathrm{~h}=85904 \mathrm{t} / \mathrm{y} \\
\mathrm{NNPC} \mathrm{CH}_{4}=\frac{(1.261+0.0696) \mathrm{M} € / \mathrm{y}}{85,904 \mathrm{t} / \mathrm{y}}=24.13 € / \mathrm{t}_{\mathrm{CH}_{4}} \\
\mathrm{NNPC}_{\mathrm{CO}_{2}}=\frac{(1.261+0.0696) \mathrm{M} € / \mathrm{y}}{127,204 \mathrm{t} / \mathrm{y}}=16.29 € / \mathrm{t}_{\mathrm{CH}_{4}}
\end{gathered}
$$

\section{Appendix C}

The $\mathrm{H}_{2}$ separation using pressure swing adsorption is calculated based on the amount of raw SynFeed produced in the SMR process. Afterwards, part of the raw SynFeed is treated by the PSA with HRF of $89 \%$. The upgraded SynFeed has to be recompressed to 22.2 bar because it is extracted from the PSA by a vacuum pump. Figure A3 shows the process flow diagram of this process. It was built in Aspen Plus, with the PSA unit modeled as component separator. Costs for equipment were taken from the literature and an economic analyzer. Utility costs are comprised of electricity costs for the vacuum pump and compressors, as well as intercooling energy. CAPEX and OPEX were calculated using base economic data as presented in chapter 4.3. Utility demand was calculated by Aspen Plus to be $1.496 \mathrm{MW}$ electricity and cooling demand each.

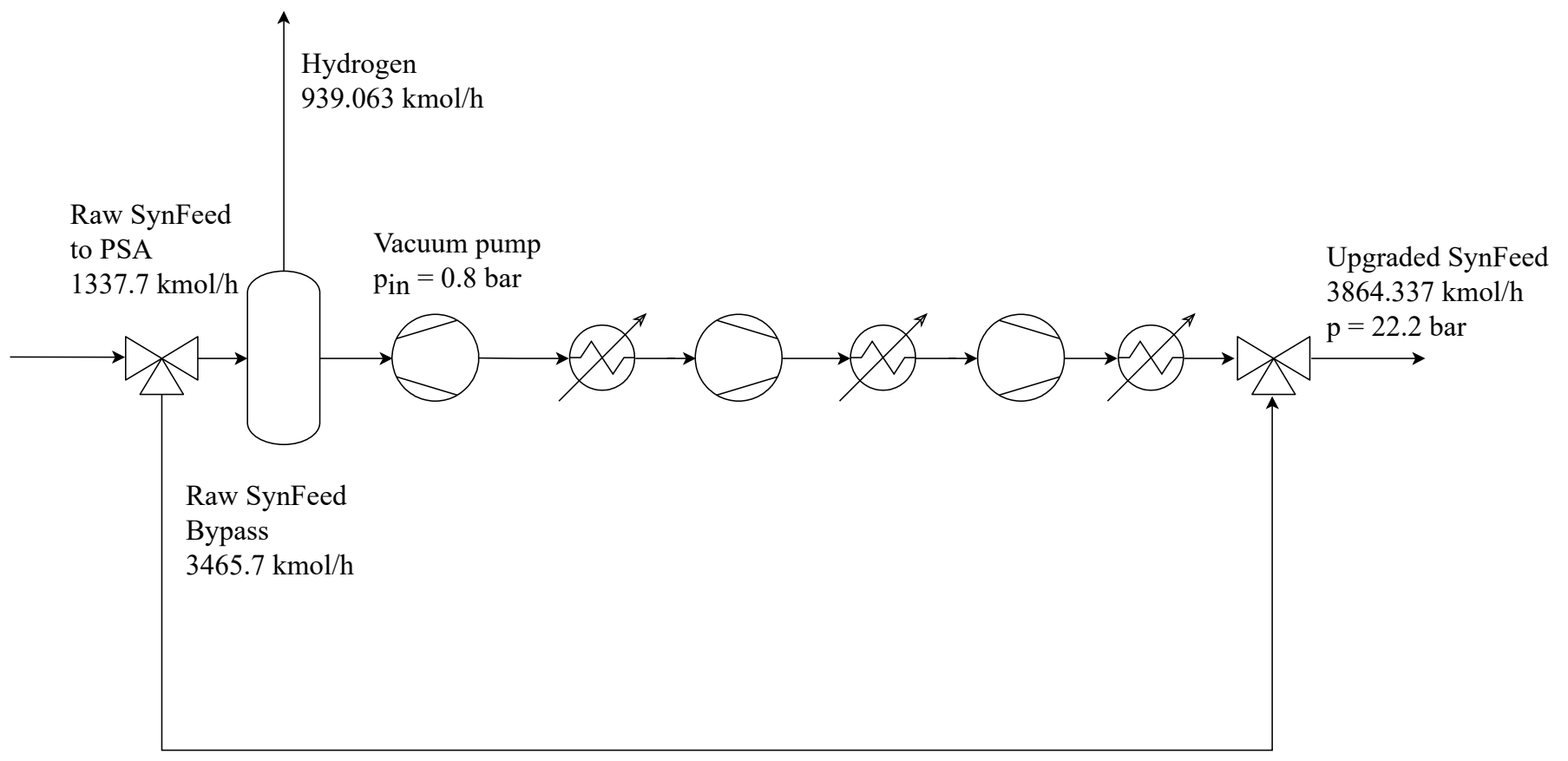

Figure A3. Process flow diagram of hydrogen removal PSA train. 


\section{Appendix D}

Pure renewable electricity-based SynFeed costs are calculated by taking a $\mathrm{H}_{2} / \mathrm{CO}_{2}$ molar-ratio of 3 and $\mathrm{CO}_{2}$ costs of $50 € / \mathrm{t}_{\mathrm{CO}_{2}}$ and $\mathrm{H}_{2}$ costs from water electrolysis with $3500 \frac{€}{\mathrm{t}_{\mathrm{H}_{2}}}$, as shown in Equations (A13) and (A14).

$$
\begin{gathered}
\frac{3 \mathrm{~mol} \mathrm{H}}{1 \mathrm{~mol} \mathrm{CO}_{2}} \rightarrow \frac{3 \cdot \frac{2 \mathrm{~g}}{\mathrm{~mol}}}{1 \cdot \frac{44 \mathrm{~g}}{\mathrm{~mol}}} \rightarrow \frac{7.3333 \mathrm{t}_{\mathrm{CO}_{2}}}{1 \mathrm{t}_{\mathrm{H}_{2}}} \\
7.333 \cdot \frac{50 €}{\mathrm{t}_{\mathrm{CO}_{2}}}+1 \frac{3500 €}{\mathrm{t}_{\mathrm{H}_{2}}}=\frac{3866.65 €}{8.3333 \mathrm{t}_{\text {SynFeed }}}=\frac{464 €}{\mathrm{t}_{\text {SynFeed }}}
\end{gathered}
$$

For the reference costs calculation of SynFeed from natural gas, the calculation from the techno-economic analysis was adopted. Only SMR and ATR concepts were investigated, because they depict the process concepts of natural gas reforming. Costs for natural gas industry prices in Germany were taken to be $2.6 \mathrm{ct} / \mathrm{kWh}$ and mean values for different gas types (e.g., low and high caloric gases) were considered, resulting in mean natural gas costs of $310 € / \mathrm{t}$. These costs were implemented in the techno-economic analysis. The lowest costs were achieved where $\mathrm{H}_{2}$ could be separated and used to substitute water electrolysis, while a more expensive approach is ATR reforming with the mixing of additional $\mathrm{CO}_{2}$, increasing the price span to $107-177 € / \mathrm{t}_{\text {synFeed }}$.

\section{Appendix E}

Tables A1 and A8 show the mass flows for the different reforming processes, as well as carbon capture from these reforming processes. The associated stream numbers are in Figures 3 and 7. 
Table A1. Mass/mole flows in SMR process with temperature and pressure state.

\begin{tabular}{|c|c|c|c|c|c|c|c|c|c|c|c|c|c|}
\hline \multirow[t]{2}{*}{ Parameter } & \multirow[t]{2}{*}{ Unit } & \multicolumn{12}{|c|}{ Stream Number } \\
\hline & & 1 & 2 & 3 & 4 & 5 & 6 & 7 & 8 & 9 & 10 & 11 & 12 \\
\hline $\mathrm{T}$ & ${ }^{\circ} \mathrm{C}$ & 25 & 457.4096 & 430.1723 & 890 & 404.9852 & 221.921 & 40 & 40 & 20 & 25 & 67.54796 & 80.07172 \\
\hline $\mathrm{p}$ & bar & 1.01325 & 26 & 25.3 & 24.6 & 23.3 & 22.6 & 22.2 & 22.2 & 1.01325 & 1.01325 & 0.25 & 1 \\
\hline Mass Flow & $\mathrm{kg} / \mathrm{h}$ & $16,042.76$ & $90,076.4$ & $106,119.2$ & $10,6119.2$ & $106,119.2$ & $106,119.2$ & $50,325.22$ & $55,793.94$ & $208,569.9$ & $10,580.2$ & $25,581.7$ & $219,150.1$ \\
\hline $\mathrm{H}_{2} \mathrm{O}$ & $\mathrm{kg} / \mathrm{h}$ & 0 & $90,076.4$ & $86,654.15$ & $64,789.12$ & $57,560.62$ & $56,053.17$ & 267.8497 & $55,785.32$ & 1306.918 & 0 & $25,581.7$ & $25,069.06$ \\
\hline $\mathrm{CO}_{2}$ & $\mathrm{~kg} / \mathrm{h}$ & 0 & 0 & 4163.086 & $19,961.71$ & 37620.31 & 41302.88 & $41,294.31$ & 8.573509 & 0 & 0 & 0 & $29,024.45$ \\
\hline $\mathrm{CO}$ & $\mathrm{kg} / \mathrm{h}$ & 0 & 0 & 21.70286 & 13907.42 & 2668.458 & 324.6558 & 324.6551 & 0.000629 & 0 & 0 & 0 & 0.011358 \\
\hline $\mathrm{H}_{2}$ & $\mathrm{~kg} / \mathrm{h}$ & 0 & 0 & 767.4507 & 6660.113 & 7468.97 & 7637.651 & 7637.622 & 0.028881 & 0 & 0 & 0 & 0.001029 \\
\hline $\mathrm{O}_{2}$ & $\mathrm{~kg} / \mathrm{h}$ & 0 & 0 & $3.30 \times 10^{-26}$ & $2.57 \times 10^{-13}$ & $2.57 \times 10^{-13}$ & $2.57 \times 10^{-13}$ & 0 & 0 & $48,748.41$ & 0 & 0 & 6542.009 \\
\hline $\mathrm{N}_{2}$ & $\mathrm{~kg} / \mathrm{h}$ & 0 & 0 & 0 & 0 & 0 & 0 & 0 & 0 & $15,8514.6$ & 0 & 0 & $158,514.6$ \\
\hline
\end{tabular}

Table A2. Mass/mole flows in ATR process with temperature and pressure state.

\begin{tabular}{|c|c|c|c|c|c|c|c|c|c|c|}
\hline \multirow[t]{2}{*}{ Parameter } & \multirow[t]{2}{*}{ Unit } & \multicolumn{9}{|c|}{ Stream Number } \\
\hline & & 1 & 2 & 3 & 4 & 5 & 6 & 7 & 8 & 9 \\
\hline $\mathrm{T}$ & ${ }^{\circ} \mathrm{C}$ & 25 & 30 & 430.4176 & 999.0331 & 443.3008 & 243.5181 & 40 & 40 & 25 \\
\hline $\mathrm{p}$ & bar & 1.01325 & 1.01325 & 25.3 & 24.6 & 23.3 & 22.6 & 22.2 & 22.2 & 1.01325 \\
\hline Mole Flow & $\mathrm{kmol} / \mathrm{hr}$ & 1000 & 2205 & 3313.463 & 5185.34 & 5185.34 & 5185.34 & 3796.082 & 1389.259 & 574.39 \\
\hline Mass Flow & $\mathrm{kg} / \mathrm{hr}$ & $16,042.76$ & $39,723.69$ & $55,766.45$ & $74,146.24$ & $74,146.24$ & $74,146.24$ & $49,115.53$ & $25,030.72$ & $18,379.79$ \\
\hline $\mathrm{H}_{2} \mathrm{O}$ & $\mathrm{kg} / \mathrm{hr}$ & 0 & $39,723.69$ & 37,780 & $36,075.33$ & $28,052.83$ & $25,240.17$ & 214.4203 & $25,025.75$ & 0 \\
\hline $\mathrm{CO}_{2}$ & $\mathrm{~kg} / \mathrm{hr}$ & 0 & 0 & 2361.578 & $15,893.04$ & $35,491.32$ & $42,362.41$ & $42,357.45$ & 495,2583 & 0 \\
\hline $\mathrm{CO}$ & $\mathrm{kg} / \mathrm{hr}$ & 0 & 0 & 15.99494 & $17,619.81$ & 5146.322 & 773.1602 & 773.1594 & 0.000849 & 0 \\
\hline $\mathrm{CH}_{4}$ & $\mathrm{~kg} / \mathrm{hr}$ & 16042.76 & 0 & $15,172.74$ & 157.6972 & 157.6972 & 157.6972 & 157.6954 & 0.001787 & 0 \\
\hline $\mathrm{O}_{2}$ & $\mathrm{~kg} / \mathrm{hr}$ & 0 & 0 & $1.09 \times 10^{-26}$ & $1.07 \times 10^{-11}$ & $1.07 \times 10^{-11}$ & $1.07 \times 10^{-11}$ & 0 & 0 & $18,379.79$ \\
\hline $\mathrm{N}_{2}$ & $\mathrm{~kg} / \mathrm{hr}$ & 0 & 0 & 0 & 0 & 0 & 0 & 0 & 0 & 0 \\
\hline
\end{tabular}


Table A3. Mass/mole flows in TRIR process with temperature and pressure state.

\begin{tabular}{|c|c|c|c|c|c|c|c|c|c|c|}
\hline \multirow[t]{2}{*}{ Parameter } & \multirow[t]{2}{*}{ Unit } & \multicolumn{9}{|c|}{ Stream Number } \\
\hline & & 1 & 2 & 3 & 4 & 5 & 6 & 7 & 8 & 9 \\
\hline $\mathrm{T}$ & ${ }^{\circ} \mathrm{C}$ & 25 & 30 & 451.3292 & 961.6535 & 448.3946 & 245.2516 & 40 & 40 & 25 \\
\hline $\mathrm{p}$ & bar & 1.01325 & 1.01325 & 25.3 & 24.6 & 23.3 & 22.6 & 22.2 & 22.2 & 1.01325 \\
\hline Mole Flow & $\mathrm{kmol} / \mathrm{hr}$ & 1000 & 1625 & 2685.697 & 3911.885 & 3911.885 & 3911.885 & 2773.133 & 1138.752 & 393.5504 \\
\hline Mass Flow & $\mathrm{kg} / \mathrm{hr}$ & $25,831.22$ & $29,274.83$ & $55,106.05$ & $67,699.19$ & $67,699.19$ & $67,699.19$ & $47,181.06$ & $20,518.14$ & $12,593.14$ \\
\hline $\mathrm{H}_{2} \mathrm{O}$ & $\mathrm{kg} / \mathrm{hr}$ & 0 & $29,274.83$ & $28,244.82$ & $29,705.86$ & $23,011.46$ & $20,672.7$ & 160.1096 & $20,512.59$ & 0 \\
\hline $\mathrm{CO}_{2}$ & $\mathrm{~kg} / \mathrm{hr}$ & $15,403.43$ & 0 & $16,584.02$ & $20,672.83$ & $37,026.67$ & $42,740.06$ & $42,734.53$ & 5.536185 & 0 \\
\hline $\mathrm{CO}$ & $\mathrm{kg} / \mathrm{hr}$ & 0 & 0 & 98.67892 & $14,669.34$ & 4260.8 & 624.4631 & 624.4624 & 0.000769 & 0 \\
\hline $\mathrm{H}_{2}$ & $\mathrm{~kg} / \mathrm{hr}$ & 0 & 0 & 237.6138 & 2545.975 & 3295.067 & 3556.771 & 3556.762 & 0.008646 & 0 \\
\hline $\mathrm{CH}_{4}$ & $\mathrm{~kg} / \mathrm{hr}$ & $10,427.79$ & 0 & 9940.921 & 105.1968 & 105.1968 & 105.1968 & 105.1954 & 0.001331 & 0 \\
\hline $\mathrm{O}_{2}{ }^{7}$ & $\mathrm{~kg} / \mathrm{hr}$ & 0 & 0 & $2.05 \times 10^{-25}$ & $3.83 \times 10^{-12}$ & $3.83 \times 10^{-12}$ & $3.83 \times 10^{-12}$ & 0 & 0 & $12,593.14$ \\
\hline $\mathrm{N}_{2}$ & $\mathrm{~kg} / \mathrm{hr}$ & 0 & 0 & 0 & 0 & 0 & 0 & 0 & 0 & 0 \\
\hline
\end{tabular}

Table A4. Mass/mole flows in BIR process with temperature and pressure state.

\begin{tabular}{|c|c|c|c|c|c|c|c|c|c|c|c|c|c|}
\hline \multirow[t]{2}{*}{ Parameter } & \multirow[t]{2}{*}{ Unit } & \multicolumn{12}{|c|}{ Stream Number } \\
\hline & & 1 & 2 & 3 & 4 & 5 & 6 & 7 & 8 & 9 & 10 & 11 & 12 \\
\hline $\mathrm{T}$ & ${ }^{\circ} \mathrm{C}$ & 25 & 455.8135 & 447.7253 & 890 & 420.8244 & 228.882 & 40 & 40 & 20 & 25 & 67.54796 & 81.84948 \\
\hline $\mathrm{p}$ & bar & 1.01325 & 26 & 25.3 & 24.6 & 23.3 & 22.6 & 22.2 & 22.2 & 1.01325 & 1.01325 & 0.25 & 1 \\
\hline Mole Flow & $\mathrm{kmol} / \mathrm{hr}$ & 1000 & 3250 & 4350.991 & 5486.642 & 5486.642 & 5486.642 & 3470.778 & 2015.864 & 5419.7 & 758 & 1710 & 6177.7 \\
\hline Mass Flow & $\mathrm{kg} / \mathrm{hr}$ & $25,831.22$ & $58,549.66$ & $84,380.88$ & $84,380.88$ & $84,380.88$ & $84,380.88$ & $48,060.07$ & $36,320.81$ & $15,5818.6$ & $19,580.07$ & $30,806.13$ & $17,5398.7$ \\
\hline $\mathrm{H}_{2} \mathrm{O}$ & $\mathrm{kg} / \mathrm{hr}$ & 0 & $58,549.66$ & 56,785 & $44,806.99$ & $38,199.62$ & $36,510.22$ & 197.2034 & $36,313.01$ & 976.3741 & 0 & $30,806.13$ & $18,728.62$ \\
\hline $\mathrm{CO}_{2}$ & $\mathrm{~kg} / \mathrm{hr}$ & $15,403.43$ & 0 & $17,492.04$ & $21,763.4$ & $37,904.65$ & $42,031.73$ & $42,023.96$ & 7.772271 & 0 & $11,675.8$ & 0 & $33,359.41$ \\
\hline $\mathrm{CO}$ & $\mathrm{kg} / \mathrm{hr}$ & 0 & 0 & 85.07972 & $13,271.57$ & 2998.337 & 371.6237 & 371.623 & 0.000648 & 0 & 0 & 0 & 0.013432 \\
\hline $\mathrm{CH}_{4}$ & $\mathrm{~kg} / \mathrm{hr}$ & $10,427.79$ & 0 & 9617.709 & 508.2159 & 508.2159 & 508.2159 & 508.2068 & 0.009124 & 0 & 7904.268 & 0 & $1.55 \times 10^{-27}$ \\
\hline $\mathrm{O}_{2}$ & $\mathrm{~kg} / \mathrm{hr}$ & 0 & 0 & $3.04 \times 10^{-25}$ & $2.33 \times 10^{-13}$ & $2.33 \times 10^{-13}$ & $2.33 \times 10^{-13}$ & 0 & 0 & $36,419.02$ & 0 & 0 & 4887.415 \\
\hline $\mathrm{N}_{2}$ & $\mathrm{~kg} / \mathrm{hr}$ & 0 & 0 & 0 & 0 & 0 & 0 & 0 & 0 & 118423.2 & 0 & 0 & $118,423.2$ \\
\hline
\end{tabular}


Table A5. Mass/Mole flows of Selexol process for SMR outlet gas with temperature and pressure state.

\begin{tabular}{ccccccccc}
\hline Parameter & Unit & \multicolumn{7}{c}{ Stream Number } \\
\hline & & $\mathbf{1}$ & $\mathbf{2}$ & $\mathbf{3}$ & $\mathbf{4}$ & $\mathbf{5}$ & $\mathbf{6}$ \\
\hline $\mathrm{T}$ & ${ }^{\circ} \mathrm{C}$ & 40 & -0.99971 & 11.44564 & 1.515331 & 10.80434 & 6.483563 & 1.835216 \\
$\mathrm{p}$ & $\mathrm{bar}$ & 22.2 & 22.2 & 22.2 & 22.2 & 10.5 & 2.15 & 0.3 \\
Mole Flow & $\mathrm{kmol} / \mathrm{h}$ & 4803.401 & 9999.338 & $10,936.05$ & 3920.286 & 53.37238 & 442.2534 & 454.4533 \\
Mass Flow & $\mathrm{kg} / \mathrm{h}$ & $55,474.06$ & 163,3025 & $1,675,774$ & $13,862.64$ & 1133.493 & $20,493.71$ & $21,387.74$ \\
$\mathrm{DEPG}$ & $\mathrm{kg} / \mathrm{h}$ & 0 & 15,30598 & 15,30598 & 0.001129 & 0.000122 & 0.002227 & 0.007401 \\
$\mathrm{CO}$ & $\mathrm{kg} / \mathrm{h}$ & 357.871 & 0.001115 & 9.813414 & 352.4788 & 4.420434 & 5.205147 & 0.186717 \\
$\mathrm{CO}$ & $\mathrm{kg} / \mathrm{h}$ & $45,519.18$ & 3952.974 & $46,279.8$ & 4236.384 & 1043.927 & $20,342.79$ & $20,940.12$ \\
$\mathrm{H}_{2}$ & $\mathrm{~kg} / \mathrm{h}$ & 8419.038 & 0.001757 & 106.9864 & 8380.434 & 68.38588 & 37.96712 & 0.631608 \\
$\mathrm{H}_{2} \mathrm{O}$ & $\mathrm{kg} / \mathrm{h}$ & 295.2538 & $9,8474.02$ & $98,722.63$ & 53.08577 & 1.970459 & 68.58509 & 443.5024 \\
$\mathrm{CH}_{4}$ & $\mathrm{~kg} / \mathrm{h}$ & 882.7134 & 0.046338 & 57.28567 & 840.2613 & 14.78934 & 39.15877 & 3.291222 \\
\hline
\end{tabular}

Table A6. Mass/Mole flows of Selexol process for ATR outlet gas with temperature and pressure state.

\begin{tabular}{ccccccccc}
\hline Parameter & Unit & \multicolumn{7}{c}{ Stream Number } \\
\hline & & $\mathbf{1}$ & $\mathbf{2}$ & $\mathbf{3}$ & $\mathbf{4}$ & $\mathbf{5}$ & $\mathbf{6}$ \\
\hline $\mathrm{T}$ & ${ }^{\circ} \mathrm{C}$ & 40 & -0.99981 & -0.99981 & 2.043752 & 12.64989 & 6.492418 & 1.698376 \\
$\mathrm{p}$ & $\mathrm{bar}$ & 22.2 & 22.2 & 22.2 & 22.2 & 10.5 & 2.15 & 0.3 \\
Mole Flow & $\mathrm{kmol} / \mathrm{h}$ & 3796.08 & 8113.983 & 8113.983 & 2903.783 & 49.84854 & 527.0901 & 377.9916 \\
Mass Flow & $\mathrm{kg} / \mathrm{h}$ & $54,140.59$ & 13,21759 & 13,21759 & $11,651.23$ & 1329.498 & $24,943.54$ & $17,799.57$ \\
$\mathrm{DEPG}$ & $\mathrm{kg} / \mathrm{h}$ & 0 & 12,38407 & 12,38407 & 0.000901 & 0.000154 & 0.002657 & 0.006017 \\
$\mathrm{CO}$ & $\mathrm{kg} / \mathrm{h}$ & 852.1054 & 0.00156 & 0.00156 & 840.8976 & 11.22036 & 10.9416 & 0.266693 \\
$\mathrm{CO}$ & $\mathrm{kg} / \mathrm{h}$ & $46,691.25$ & 3218.225 & 3218.225 & 4440.694 & 1261.543 & $24,819.98$ & $17,430.37$ \\
$\mathrm{H}_{2}$ & $\mathrm{~kg} / \mathrm{h}$ & 6187.051 & 0.000724 & 0.000724 & 6163.267 & 51.55269 & 23.52053 & 0.265748 \\
$\mathrm{H}_{2} \mathrm{O}$ & $\mathrm{kg} / \mathrm{h}$ & 236.1789 & $80,134.28$ & $80,134.28$ & 39.96198 & 1.949985 & 81.90781 & 368.2506 \\
$\mathrm{CH}_{4}$ & $\mathrm{~kg} / \mathrm{h}$ & 174.0018 & 0.005658 & 0.005658 & 166.41 & 3.231662 & 7.181761 & 0.410241 \\
\hline
\end{tabular}

Table A7. Mass/Mole flows of Selexol process for TRIR outlet gas with temperature and pressure state.

\begin{tabular}{ccccccccc}
\hline Parameter & Unit & \multicolumn{7}{c}{ Stream Number } \\
\hline & & $\mathbf{1}$ & $\mathbf{2}$ & $\mathbf{3}$ & $\mathbf{4}$ & $\mathbf{5}$ & $\mathbf{6}$ \\
\hline $\mathrm{T}$ & ${ }^{\circ} \mathrm{C}$ & 40 & -0.99975 & 15.95864 & 3.017213 & 15.09966 & 6.317703 & 1.427384 \\
$\mathrm{p}$ & $\mathrm{bar}$ & 22.2 & 22.2 & 22.2 & 22.2 & 10.5 & 2.15 & 0.3 \\
Mole Flow & $\mathrm{kmol} / \mathrm{h}$ & 2773.133 & 6260.326 & 7209.441 & 1881.04 & 56.86575 & 605.3016 & 298.4395 \\
Mass Flow & $\mathrm{kg} / \mathrm{h}$ & $52,008.21$ & $1,022,311$ & $1,067,134$ & 9179.803 & 1992.169 & $28,999.04$ & $14,060.38$ \\
$\mathrm{DEPG}$ & $\mathrm{kg} / \mathrm{h}$ & 0 & $958,154.1$ & $958,154.1$ & 0.000681 & 0.000268 & 0.002981 & 0.004562 \\
$\mathrm{CO}$ & $\mathrm{kg} / \mathrm{h}$ & 688.3519 & 0.000658 & 17.76797 & 681.4286 & 10.84441 & 6.809869 & 0.11304 \\
$\mathrm{CO}$ & $\mathrm{kg} / \mathrm{h}$ & $47,106.75$ & 2513.095 & $47,109.29$ & 4450.059 & 1940.007 & $28,884.21$ & $13,771.98$ \\
$\mathrm{H}_{2}$ & $\mathrm{~kg} / \mathrm{h}$ & 3920.659 & 0.00022 & 46.73519 & 3910.02 & 36.09693 & 10.5568 & 0.081235 \\
$\mathrm{H}_{2} \mathrm{O}$ & $\mathrm{kg} / \mathrm{h}$ & 176.4907 & $61,643.7$ & $61,799.32$ & 26.57529 & 2.389313 & 93.37981 & 288.0509 \\
$\mathrm{CH}_{4}$ & $\mathrm{~kg} / \mathrm{h}$ & 115.9581 & 0.002176 & 7.0713 & 111.7192 & 2.830401 & 4.080083 & 0.158639 \\
\hline
\end{tabular}

Table A8. Mass/Mole flows of Selexol process for BIR outlet gas with temperature and pressure state.

\begin{tabular}{|c|c|c|c|c|c|c|c|c|}
\hline \multirow[t]{2}{*}{ Parameter } & \multirow[t]{2}{*}{ Unit } & \multicolumn{7}{|c|}{ Stream Number } \\
\hline & & 1 & 2 & 3 & 4 & 5 & 6 & 7 \\
\hline $\mathrm{T}$ & ${ }^{\circ} \mathrm{C}$ & 40 & -0.99973 & 13.93686 & 2.261735 & 13.22809 & 6.440842 & 1.634381 \\
\hline $\mathrm{p}$ & bar & 22.2 & 22.2 & 22.2 & 22.2 & 10.5 & 2.15 & 0.3 \\
\hline Mole Flow & $\mathrm{kmol} / \mathrm{h}$ & 3470.778 & 7500.608 & 8435.161 & 2586.331 & 50.24119 & 544.7454 & 352.0199 \\
\hline Mass Flow & $\mathrm{kg} / \mathrm{h}$ & $52,977.16$ & $1,224,804$ & 1268434 & $10,783.58$ & 1438.525 & $25,860.25$ & $16,578.2$ \\
\hline DEPG & $\mathrm{kg} / \mathrm{h}$ & 0 & $1,147,948$ & $1,147,948$ & 0.000836 & 0.000172 & 0.002732 & 0.005559 \\
\hline $\mathrm{CO}$ & $\mathrm{kg} / \mathrm{h}$ & 409.6443 & 0.00064 & 10.73663 & 404.5428 & 5.634102 & 4.992375 & 0.109517 \\
\hline $\mathrm{CO}_{2}$ & $\mathrm{~kg} / \mathrm{h}$ & $46,323.48$ & 2987.874 & $46,325.14$ & 4359.737 & 1373.081 & $25,729.13$ & $16,235.06$ \\
\hline $\mathrm{H}_{2}$ & $\mathrm{~kg} / \mathrm{h}$ & 5466.453 & 0.000536 & 66.27093 & 5446.912 & 46.72598 & 19.34764 & 0.196775 \\
\hline $\mathrm{H}_{2} \mathrm{O}$ & $\mathrm{kg} / \mathrm{h}$ & 217.3796 & $73,868.02$ & $74,048.72$ & 35.78228 & 1.996201 & 84.34238 & 341.6704 \\
\hline $\mathrm{CH}_{4}$ & $\mathrm{~kg} / \mathrm{h}$ & 560.2021 & 0.015891 & 34.69611 & 536.6099 & 11.08706 & 22.43985 & 1.153309 \\
\hline
\end{tabular}




\section{References}

1. Olah, G.A.; Goeppert, A.; Prakash, G.K.S. Beyond Oil and Gas: The Methanol Economy, 2nd ed.; Wiley-VCH Verlag GmbH \& Co. KGaA: Weinheim, Germany, 2009; ISBN 9783527324224.

2. Davis, R.; Aden, A.; Pienkos, P.T. Techno-economic analysis of autotrophic microalgae for fuel production. Appl. Energy 2011, 88, 3524-3531. [CrossRef]

3. Eichlseder, H.; Klell, M.; Trattner, A. Wasserstoff in der Fahrzeugtechnik—Erzeugung, Speicherung, Anwendung; Springer: New York, NY, USA, 2018; ISBN 9783658204464.

4. Chew, K.W.; Yap, J.Y.; Show, P.L.; Suan, N.H.; Juan, J.C.; Ling, T.C.; Lee, D.J.; Chang, J.S. Microalgae biorefinery: High value products perspectives. Bioresour. Technol. 2017, 229, 53-62. [CrossRef]

5. Lee, R.A.; Lavoie, J.M. From first- to third-generation biofuels: Challenges of producing a commodity from a biomass of increasing complexity. Anim. Front. 2013, 3, 6-11. [CrossRef]

6. Wang, W.C. Techno-economic analysis of a bio-refinery process for producing Hydro-processed Renewable Jet fuel from Jatropha. Renew. Energy 2016, 95, 63-73. [CrossRef]

7. Wang, W.C. Techno-economic analysis for evaluating the potential feedstocks for producing hydro-processed renewable jet fuel in Taiwan. Energy 2019, 179, 771-783. [CrossRef]

8. ASTM. ASTM D7566-18a. Standard Specification for Aviation Turbine Fuel Containing Synthesized Hydrocarbons; ASTM: West Consohocken, PA, USA, 2017.

9. Zhao, X.; Joseph, B.; Kuhn, J.; Ozcan, S. Biogas Reforming to Syngas: A Review. iScience 2020, 23, 101082. [CrossRef]

10. Minh, D.P.; Siang, T.J.; Vo, D.V.N.; Phan, T.S.; Ridart, C.; Nzihou, A.; Grouset, D. Hydrogen Production from Biogas Reforming: An Overview of Steam Reforming, Dry Reforming, Dual Reforming, and Tri-Reforming of Methane; Elsevier Ltd.: Amsterdam, The Netherlands, 2018; ISBN 9780128111970.

11. Di Marcoberardino, G.; Vitali, D.; Spinelli, F.; Binotti, M.; Manzolini, G. Green hydrogen production from raw biogas: A techno-economic investigation of conventional processes using pressure swing adsorption unit. Processes 2018, 6, 19. [CrossRef]

12. De Rosa, F.; Smyth, B.M.; McCullough, G.; Goguet, A. Using multi-criteria and thermodynamic analysis to optimize process parameters for mixed reforming of biogas. Int. J. Hydrogen Energy 2018, 43, 18801-18813. [CrossRef]

13. Montenegro Camacho, Y.S.; Bensaid, S.; Piras, G.; Antonini, M.; Fino, D. Techno-economic analysis of green hydrogen production from biogas autothermal reforming. Clean Technol. Environ. Policy 2017, 19, 1437-1447. [CrossRef]

14. Madeira, J.G.F.; Delgado, A.R.S.; Boloy, R.A.M.; Coutinho, E.R.; Loures, C.C.A. Exergetic and economic evaluation of incorporation of hydrogen production in a cassava wastewater plant. Appl. Therm. Eng. 2017, 123, 1072-1078. [CrossRef]

15. Chein, R.Y.; Hsu, W.H. Analysis of syngas production from biogas via the tri-reforming process. Energies 2018, 11, 1075. [CrossRef]

16. Gong, J.; You, F. Global optimization for sustainable design and synthesis of algae processing network for $\mathrm{CO} 2 \mathrm{mitigation}$ and biofuel production using life cycle optimization. AIChE J. 2014. [CrossRef]

17. Gong, J.; You, F. Value-added chemicals from microalgae: Greener, more economical, or both? ACS Sustain. Chem. Eng. 2015, 3, 82-96. [CrossRef]

18. Wang, B.; Gebreslassie, B.H.; You, F. Sustainable design and synthesis of hydrocarbon biorefinery via gasification pathway: Integrated life cycle assessment and technoeconomic analysis with multiobjective superstructure optimization. Comput. Chem. Eng. 2013, 52, 55-76. [CrossRef]

19. Galanopoulos, C.; Kenkel, P.; Zondervan, E. Superstructure optimization of an integrated algae biorefinery. Comput. Chem. Eng. 2019, 130, 106530. [CrossRef]

20. Gebreslassie, B.H.; Waymire, R.; You, F. Sustainable design and synthesis of algae-based biorefinery for simultaneous hydrocarbon biofuel production and carbon sequestration. AIChE J. 2013. [CrossRef]

21. Levalley, T.L.; Richard, A.R.; Fan, M. The progress in water gas shift and steam reforming hydrogen production technologies-A review. Int. J. Hydrogen Energy 2014, 39, 16983-17000. [CrossRef]

22. Katofsky, R.E. The Production of Fluid Fuels from Biomass. Master's Thesis, Princeton University, Princeton, NJ, USA, 1993.

23. Julián-Durán, L.M.; Ortiz-Espinoza, A.P.; El-Halwagi, M.M.; Jiménez-Gutiérrez, A. Techno-economic assessment and environmental impact of shale gas alternatives to methanol. ACS Sustain. Chem. Eng. 2014, 2, 2338-2344. [CrossRef]

24. Hamelinck, C.N.; Faaij, A.P.C. Future prospects for production of methanol and hydrogen from biomass. J. Power Sources 2002, 111, 1-22. [CrossRef]

25. Olajire, A.A. CO2 capture and separation technologies for end-of-pipe applications-A review. Energy 2010, 35, 2610-2628. [CrossRef]

26. Dyment, J.; Watanasiri, S. Acid Gas Cleaning Using Amine Solvents: Validation with Experimental and Plant Data; Aspen Technology Inc.: Bedford, MA, USA, 2015; pp. 2-10.

27. Ramzan, N.; Shakeel, U.; Gungor, A.; Zaman, M. Techno-Economic Analysis of Selexol and Sulfinol Processes for Pre-Combustion $\mathrm{CO}_{2}$ Capture. In Proceedings of the 4th International Conference on Power Generation Systems and Renewable Energy Technologies, PGSRET, Islamabad, Pakistan, 10-12 September 2018.

28. Klein-Marcuschamer, D.; Turner, C.; Allen, M.; Gray, P.; Dietzgen, R.G.; Gresshoff, P.M.; Hankamer, B.; Heimann, K.; Scott, P.T.; Stephens, E.; et al. Technoeconomic analysis of renewable aviation fuel from microalgae, Pongamia pinnata, and sugarcane. Biofuels Bioprod. Biorefining 2013, 7, 416-428. [CrossRef]

29. VDI Gesellschaft. VDI-Wärmeatlas, 2005th ed.; Springer: Berlin/Heidelberg, Germany, 2005. 
30. Spallina, V.; Pandolfo, D.; Battistella, A.; Romano, M.C.; Van Sint Annaland, M.; Gallucci, F. Techno-economic assessment of membrane assisted fluidized bed reactors for pure H2 production with CO2 capture. Energy Convers. Manag. 2016, 120, 257-273. [CrossRef]

31. Tsunatu, D.; Mohammed-Dabo, I.; Waziri, S. Technical Evaluation of Selexol-Based CO2 Capture Process for a Cement Plant. Br. J. Environ. Clim. Chang. 2015, 5, 52-63. [CrossRef]

32. Danlami, T. Economic Evaluation of Selexol-Based $\mathrm{CO}_{2}$ Capture Process for a Cement Plant Using Post-Combustion Technology. Int. J. Sci. Res. Sci. Technol. 2015, 1, 194-203.

33. Turton, R.; Bailie, R.C.; Whiting, W.B. Analysis, Synthesis, and Design of Chemical Processes; Pearson: Harlow, UK, 1998; Volume 36, ISBN 9780132618120.

34. Peters, M.S.; Timmerhaus, K.D.; West, R.E. Plant Design and Economics for Chemical Engineers, 5th ed.; Glandt, E.D., Klein, M.T., Edgar, T.F., Eds.; McGraw-Hill: New York, NY, USA, 2003.

35. Cormos, A.M.; Szima, S.; Fogarasi, S.; Cormos, C.C. Economic assessments of hydrogen production processes based on natural gas reforming with carbon capture. Chem. Eng. Trans. 2018, 70, 1231-1236. [CrossRef]

36. Fachagentur Nachwachsende Rohstoffe e.V. Leitfaden Biogasaufbereitung und -Einspeisung; FNR; 2014. Available online: https: //mediathek.fnr.de/broschuren/bioenergie/biogas/leitfaden-biogasaufbereitung.html (accessed on 20 May 2021).

37. Kenkel, P.; Wassermann, T.; Rose, C.; Zondervan, E. A generic superstructure modeling and optimization framework on the example of bi-criteria Power-to-Methanol process design. Comput. Chem. Eng. 2021, 150, 107327. [CrossRef]

38. Von Liebner, W.; Wagner, M. MtSynfuels ${ }^{\circledR}$, die effiziente und wirtschaftliche Alternative zu Fischer-Tropsch-Treibstoffen. Erdoel Erdgas Kohle 2004, 120, 323-326.

39. Wassermann, T.; Schnuelle, C.; Kenkel, P.; Zondervan, E. Power-to-Methanol at Refineries as a Precursor to Green Jet Fuel Production: A Simulation and Assessment Study. In Computer Aided Chemical Engineering; Elsevier B.V.: Amsterdam, The Netherlands, 2020; Volume 48, pp. 1453-1458. 